ROBERTO MAXIMILIANO CARRASCO NAVARRO

\title{
Avaliação clínico-laboratorial de pacientes co-infectados com o vírus da hepatite C e HIV em relação ao tipo de terapia antirretroviral recebida
}

Dissertação apresentada à Faculdade de Medicina da Universidade de São Paulo para obtenção do título de Mestre em Ciências 
ROBERTO MAXIMILIANO CARRASCO NAVARRO

\section{Avaliação clínico-laboratorial de pacientes co-infectados com o vírus da hepatite C e HIV em relação ao tipo de terapia antirretroviral recebida}

Dissertação apresentada à Faculdade de Medicina da Universidade de São Paulo para obtenção do título de Mestre em Ciências

Área de concentração: Doenças Infecciosas e Parasitárias

Orientador: Prof. Dr. Antonio Alci Barone 
A Nestor Maximiliano Carrasco Carrasco (in memorian), meu Pai 


\section{AGRADECIMENTOS}

À Rosa, minha Mãe e Amiga, sempre presente.

À Gladys e Camila, minhas Chefas, pela paciência e apoio ao entender meus estados de humor e ausências.

À minha Família - os Carrasco e os Navarro - pelo carinho sincero e incondicional nos momentos difíceis.

Ao Dr. Antonio Alci Barone, grande Professor e melhor Amigo.

Aos colegas do HC-FMUSP - Dr. Francisco França, Dra. Fátima Mitiko Tengan, Dra. Maria Cássia Jacintho Mendes Corrêa - obrigado pelo apoio desde o primeiro dia.

Aos colegas do LIM-47 - Dr. Evaldo Stanislau Affonso de Araújo, Dra. Ana Teresa Rodriguez Viso, Norma de Paula Cavalheiro e Carlos Eduardo de Melo - pela sincera amizade.

Às Secretárias da Pós-Graduação - Rosemeire e Roseli - pela paciência em entender meu português desde os meus primeiros telefonemas dados do Peru.

À Antonia Magali Dias de Souza, pelo profissionalismo na digitação e formatação deste trabalho.

Este trabalho foi desenvolvido graças ao apoio do programa PEC-PG da CNPq. 


\section{SUMÁRIO}

Lista de Abreviaturas

Lista de Figuras

Lista de Tabelas

Lista de Gráficos

Lista de Anexos

Resumo

Summary

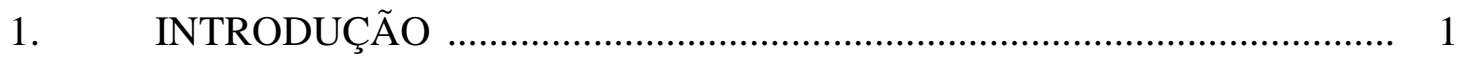

2. REVISÃO DA LITERATURA ….................................................... 5

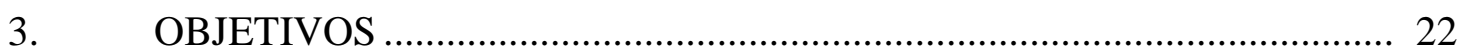

4. CASUÍSTICA E MÉTODOS _......................................................... 23

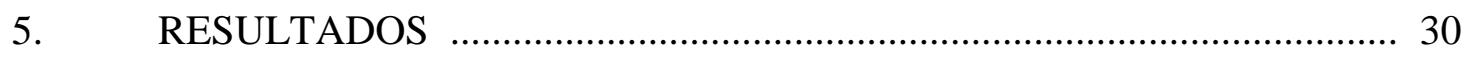

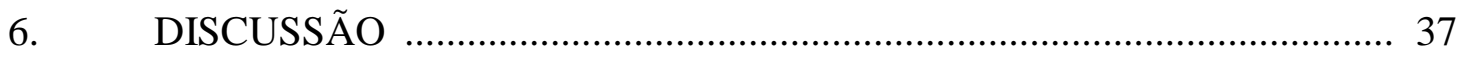

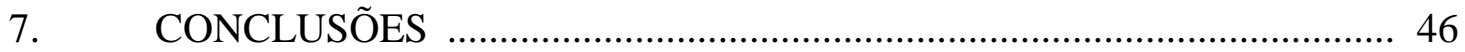

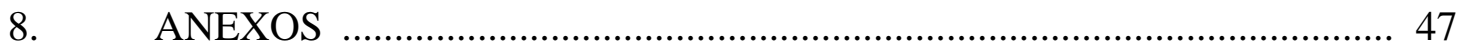

9. REFERÊNCIAS BIBLIOGRÁFICAS ................................................ 54 


\section{LISTA DE ABREVIATURAS}

AIDS Acquired Immune Deficiency Syndrome (Síndrome da Imunodeficiência Adquirida)

ALT Alaninoaminotransferase

BT Bilirrubina Total

C Core

CDC Centers for Disease Control and Prevention (Centro de Controle e Prevenção de Doenças)

CIP Com Inibidor de Protease

ELISA Enzyme-Linked Immunosorbant Assay (Imunoenzimático de Fase Sólida)

FDA Food and Drug Administration

g/d Gramas por Dia

GGT Gamma Glutamyl Transpeptidase

HAART Highly Active Antiretroviral Therapy (Terapia Antirretroviral Altamente Ativa)

HIV Human Immunodeficiency Virus (Vírus da Imunodeficiência Humana)

IC Intervalo de Confiança

IVU Intravenous Drug Users (Usuários de Drogas Intravenosas)

NNRTI Non-Nucleoside Reverse Transcriptase Inhibitors

NS5 Non-Structural Protein 5 (Não-Estrutural 5)

OMS Organização Mundial da Saúde

PCR Polymerase Chain Reaction (Reação em Cadeia pela Polimerase)

RIBA Reactive Immunoblot Assay

RNA Ribonucleic Acids (Ácido Ribonucléico) 
RR Risk Ratio (Risco Relativo)

SIP Sem Inibidor de Protease

TGO Transaminase Glutâmico Oxaloacética

TGP Transaminase Glutâmico Pirúvica

TP Tempo de Protombina

ULN Upper Limit of Normal (Acima do Limite Normal)

VHB Vírus da Hepatite B

VHC Vírus da Hepatite C

w/ PID With Protein Inhibitors Drugs (Com Drogas Inibidoras de Protease)

w/o PID Without Protein Inhibitors Drugs (Sem Drogas Inibidoras de Protease) 


\section{LISTA DE FIGURAS}

Figura 1 Estrutura do genoma do vírus da hepatite C........................................ 6

Figura 2 Árvore filogenética do vírus da hepatite $\mathrm{C}$ mostrando os tipos de 1 ao $6 \mathrm{e}$

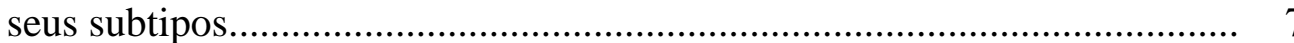




\section{LISTA DE TABELAS}

Tabela 1 Prevalência estimada do VHC e número de pessoas infectadas por dados da OMS

Tabela 2 Prevalência de VHC em pacientes infectados por HIV

Tabela 3 Características demográficas dos pacientes co-infectados com HIV-VHC de acordo com o tipo de terapia antirretroviral recebida.

Tabela 4 Fatores de risco identificados nos pacientes co-infectados com HIV-VHC de acordo com o tipo de terapia antirretroviral recebida

Tabela 5 Consumo de álcool nos pacientes co-infectados com HIV-VHC de acordo com o tipo de terapia antirretroviral recebida.

Tabela 6 Presença de doenças definidoras de $\operatorname{AIDS}^{(*)}$ nos pacientes co-infectados com HIV-VHC de acordo com o tipo de terapia antirretroviral recebida.... 33

Tabela 7 Consumo de drogas hepatotóxicas nos pacientes co-infectados com HIVVHC de acordo com o tipo de terapia antirretroviral recebida.

Tabela 8 Presença de sintomas relacionados à doença hepática nos pacientes coinfectados com HIV-VHC de acordo com o tipo de terapia antirretroviral recebida.

Tabela 9 Parâmetros bioquímicos e virológicos (valor médio, mínimo, máximo e desvio padrão) avaliados nos pacientes co-infectados com HIV-VHC de acordo com o tipo de terapia antirretroviral recebida.

Tabela 10 Avaliação do grau de fibrose na biopsia hepática nos pacientes coinfectados com HIV-VHC de acordo com o tipo de terapia antirretroviral recebida.

Tabela 11 Avaliação do grau de atividade necro-inflamatória nos pacientes coinfectados com HIV-VHC de acordo com o tipo de terapia antirretroviral recebida. 


\section{LISTA DE GRÁFICOS}

Gráfico 1 Prevalência de anti-VHC em pacientes HIV em acompanhamento na clínica do Hospital John Hopkins $(n=1,955)$ de acordo com a categoria de risco auto-reportada.. 


\section{LISTA DE ANEXOS}

Anexo 1 Tabela de obtenção de dados................................................................ 47

Anexo 2 Critério Rio de Janeiro/Caracas de definição de caso de Aids (Ministério

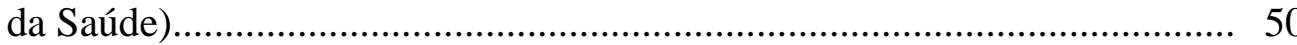

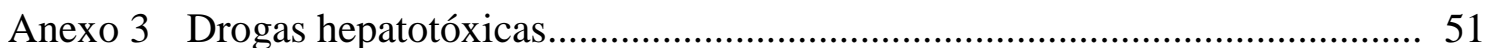

Anexo 4 Critérios de semiquantificação das biopsias hepáticas de acordo com o Consenso Nacional sobre a Classificação das Hepatites Crônicas (Projeto do Clube de Patologia Hepática da Sociedade Brasileira de Patologia, aprovado pela Sociedade Brasileira de Hepatologia (GED 19(3)137-140: Mai/Jun 2000) 


\section{RESUMO}

CARRASCO NAVARRO, R.M. Avaliação clínico-laboratorial de pacientes coinfectados com o vírus da hepatite C e HIV em relação ao tipo de terapia antirretroviral recebida. São Paulo, 2004. 73p. Dissertação (Mestrado) Faculdade de Medicina, Universidade de São Paulo.

Para avaliar as características clínico-laboratoriais dos pacientes co-infectados com HIV e VHC, foram revisados os prontuários de pacientes atendidos no Núcleo de Extensão para Atendimento de Pacientes com HIV/AIDS (Casa da AIDS) da Divisão de Clínica de Moléstias Infecciosas e Parasitárias do Hospital das Clínicas da Faculdade de Medicina da Universidade de São Paulo, de acordo com o esquema antirretroviral que receberam pelo menos com seis meses de antecedência da primeira biopsia hepática realizada.

Foram pesquisados os 3.512 prontuários de pacientes em acompanhamento na Casa da AIDS à procura de casos de conversão sorológica para o VHC. Desses pacientes, 435 não tinham feito nenhuma avaliação, sendo possível discriminar a presença de sorologia só em 3.077 pacientes, dos quais $468(15,20 \%)$ apresentaram positividade para o VHC.

Fizeram parte da amostra 111 pacientes, dos quais 74 foram tratados com medicamentos inibidores de protease (grupo CIP) e 37 tratados sem medicamentos inibidores de protease (grupo SIP) dentro do seu esquema antirretroviral altamente ativo (HAART).

Dados epidemiológicos, clínicos e laboratoriais foram pesquisados com referência a seu comportamento separados de acordo com o tipo de terapia antirretroviral recebida (com ou sem inibidor da protease).

Foi observada uma população jovem (média de 41 anos em ambos os grupos) de predominância masculina (74,3\% no grupo CIP e 51,4\% no grupo SIP) de raça branca (CIP 80,6\% e SIP 94,4\%) de grau educacional não profissional (CIP 92,9\% e SIP 100\%). Tinham antecedentes de risco para ambas as infecções em 93,2\% dos pacientes CIP e $89,2 \%$ dos SIP. E com um consumo considerado habitual no grupo CIP em $40 \%$ dos casos e nenhum em 42,3\% dos casos no grupo SIP.

Presença de alguma doença definidora de AIDS durante o curso da doença foi identificado unicamente no $18,9 \%$ dos casos CIP e no $13,5 \%$ dos casos SIP. Consumo de drogas hepatotóxicas foi observado ( $8,1 \%$ no grupo CIP e $13,5 \%$ no SIP).

Houve elevação média das enzimas hepáticas em ambos os grupos (TGO 52,1 no grupo CIP e 53,2 no SIP) em ausência de sintomas relacionáveis com doença hepática (16,2\% em ambos os grupos). A média de CD4 em ambos os grupos foi maior de $350 \mathrm{cel} / \mathrm{ml}$ (CIP 362,2 e SIP 378,1).

O grau de fibrose foi predominantemente baixo em ambas as populações (0-2 em 63,6\% dos pacientes CIP e $80 \%$ dos casos SIP) com atividade necro-inflamatória somada de entre 5-7 no 51,3\% dos pacientes CIP e 42,9\% do grupo SIP.

Sugere-se realização de biopsia seqüencial para melhor avaliar a evolução da doença hepática de acordo com o esquema HAART recebido. 


\section{SUMMARY}

\section{CARRASCO NAVARRO, R.M. Clinical and laboratorial evaluation of patients co-infected with hepatitis $C$ virus and HIV in relationship with the antiretroviral therapy received. São Paulo, 2004. 73p. Dissertação (Mestrado) - Faculdade de Medicina, Universidade de São Paulo.}

In order to evaluate the clinical and laboratorial characteristics of the co-infected HIV-HCV patients, medical charts were reviewed from the AIDS outpatient clinic, of the department of Infectious Diseases, São Paulo University School of Medicine, according to the antiretroviral treatment taken at least six months prior to the first liver biopsy performed.

A total of 3.512 medical charts were reviewed from patients followed by the AIDS outpatient clinic, in search of patients of serological conversion for HCV. Of these patients 435 were never tested for HCV. From the 3.077 patients who had performed HCV serology, 468 of them $(15,20 \%)$ were positive for the virus.

The sample consisted of 111 patients. Were treated with protease inhibitor drugs (w/ PID group) 74, and 37 without protease inhibitor drugs (w/o PID group), according to their Highly Active Anti-Retroviral Therapy (HAART). Epidemiological, clinical and laboratorial data were analyzed according to the antiretroviral therapy received (with or without protease inhibitors).

It was observed a young population (mean age of 41 years old in both groups), predominantly male (74,3\% w/ PID, and 51,4\% w/o PID), white (80,6\% w/ PID, and $94,4 \%$ w/o PID), non-professional educational degree (92,9\% w/ PID, and 100\% w/o PID). The 93,2\% w/ PID were, and 89,2\% w/o PID of the patients had risk factors for both HIV and HCV. A usual alcoholic intake was observed in $40 \%$ of the w/ PID group, and no alcohol use was observed in $42,3 \%$ of the w/o PID group.

The presence of AIDS defining diseases during the time of disease were observed only on $18,9 \%$ of the w/ PID group, and on 13,5\% of the w/o PID group. Hepatotoxic drugs intake was observed in $8,1 \%$ of the w/ PID group, and in 13,5\% of the w/o PID group.

An average elevation of liver enzymes was observed in both groups (TGO 52,1 w/ PID, and 53,2 w/o PID), in absence of liver disease-related symptoms (16,2\% in both groups). The CD4 mean in both groups was above $350 \mathrm{cel} / \mathrm{ml}(362,2 \mathrm{w} / \mathrm{PID}$ and 378,1 w/o PID).

Fibrosis degree was predominantly low on both populations (0-2 in $63,6 \%$ of patients w/ PID and $80 \%$ of patients w/o PID), with cumulative necro-inflamatory activity between 5-7 in 51,3\% of patients w/ PID and 42,9\% of patients w/o PID.

We suggest that a new liver biopsy should be performed in order to better evaluate the development of the hepatic disease according to the HAART received. 


\section{1 - INTRODUÇÃO}

$\mathrm{O}$ vírus da hepatite $\mathrm{C}$ é um vírus de descobrimento relativamente recente. Com o desenvolvimento das técnicas laboratoriais para identificação dos vírus das hepatites A e B, descobre-se na década de setenta um grupo de pacientes que desenvolviam enfermidade crônica hepática relacionada com as transfusões sangüíneas cujo agente etiológico não era cultivável nem era detectável com os meios disponíveis de diagnóstico na época, sendo então proposta a existência de um agente, provavelmente viral, que desenvolvia uma enfermidade que se denominou como “hepatites não-A, não-B”. (11)

Somente em 1989 a Chiron Corporation, em colaboração com o CDC de Atlanta logram a identificação do vírus que atualmente conhecemos como o vírus da hepatite C; a partir desse instante iniciam-se as investigações para desenvolver um meio de diagnóstico acessível a toda a população assim como o estudo de sua epidemiologia e seu tratamento. (30)

Estudos posteriores mostraram que mais de $60 \%$ dos pacientes classificados como portadores do vírus da hepatites não-A, não-B deviam ser reclassificados como portadores do vírus da hepatite C. A transmissão do vírus foi relacionada com o número de unidades de sangue transfundidos, sendo freqüentemente encontrado em 
hemofílicos e naqueles pacientes renais que participavam de programas de hemodiálises e precisavam de terapia transfusional intensiva. (11)

Logo foram observados outros fatores de risco relacionados com a transmissão do VHC: uso de droga intravenosa e fatores ocupacionais como exposição a fluídos corporais de pacientes contaminados. (9)

Existem formas de transmissão como a sexual e a materno-fetal cuja importância epidemiológica ainda não foi totalmente elucidada. $(22,27)$

No momento, estima-se que pelo menos $2 \%$ da população mundial tenha a infecção, calculando-se que 28.000 novas infecções pelo vírus ocorrem anualmente nos Estados Unidos e aproximadamente 30\% delas são clinicamente identificáveis, sendo a maior parte de casos assintomáticos. (9)

A co-infecção com o vírus HIV-1 tem sido cada vez mais estudada. Sabe-se que existem populações onde o risco de co-infecção pode ser de até 90\% (usuários de drogas intravenosas, por exemplo); por outro lado, em populações onde não houve contato nenhum com o mundo contemporâneo, como nas populações indígenas da Amazônia brasileira. A soroprevalência desta hepatite é quase nula; porém, ainda é preciso esclarecer as verdadeiras taxas de co-infecção por regiões e grupos populacionais (56). A importância do VHC, a partir do ano 1989 em que a Chiron Corporation finalmente conseguiu isolá-lo e colocar no mercado mundial uma sorologia para sua identificação, não tem parado de crescer. Grandes grupos de trabalho de nível mundial disputam a supremacia com o apoio da indústria farmacêutica no desenvolvimento de medicamentos que sejam eficazes no seu tratamento, no entendimento da cinética e compreensão da sua história natural. 
Muito se avançou em termos de conhecimento a partir desse momento, principalmente a respeito da história natural do agente, fatores epidemiológicos e principalmente aspecto relativo a sua incidência mundial.

Em estudos epidemiológicos, chegou-se a reconhecer uma surpreendente prevalência de $40 \%$ em algumas regiões, como na cidade do Cairo, Egito. (86)

Mais importante ainda foi o descobrimento, devido aos pontos comuns de exposição, da grande associação deste vírus com o vírus da imunodeficiência humana (HIV) principalmente em certos grupos de risco (como os usuários de drogas intravenosas, por exemplo). Nesses grupos, a ação do vírus, a cinética viral e sua verdadeira importância são aspectos muito importantes, ainda não bem estudados. $(21,74,80)$

Desde 1996, ano em que começa a ser aplicada a HAART nos pacientes com AIDS, são consideradas cada vez mais importantes as co-morbidades potencialmente fatais, uma das quais é o VHC. O fato dos pacientes infectados pelo HIV terem uma maior expectativa de vida pelo uso desta terapia, faz com que seja cada vez mais relevante o impacto das co-infecções, especialmente a hepatite $\mathrm{C}$.

Recentes estudos apontam para o fato de que nos pacientes co-infectados a resposta antiviral do VHC ao tratamento com Interferon e Ribavirina, padronizado na atualidade, seria similar naqueles que não o são. Fato importante de se ressaltar é a maior velocidade de evolução de doença hepática associada à hepatite viral crônica neste grupo de pacientes. $(30,34,64)$

O presente trabalho tem como objetivo principal estudar uma população de coinfectados HIV-VHC em atendimento no centro de pacientes soropositivos ao vírus 
HIV associado à Faculdade de Medicina da Universidade de São Paulo e descrever suas características clínicas, epidemiológicas e laboratoriais. 


\section{2 - REVISÃO DA LITERATURA}

\subsection{Taxonomia}

A análise da sequiência de ácido nucléico do VHC tem demonstrado uma diversidade de até $30 \%$ do genoma VHC.

Levando-se em conta essa variabilidade, as diferentes amostras do VHC foram divididas em quatro categorias: tipos, subtipos, isolados e quasispécies, identificadas por métodos de genotipagem, onde a identificação das seqüências genômicas tipoespecíficas são obtidas a partir da análise do produto da PCR e técnicas de sorotipagem que se baseiam na reação de anticorpos presentes no soro, com peptídeos antigênicos tipo-específicos.

Para padronizar as várias nomenclaturas descritas em diferentes centros de pesquisa do mundo, um sistema único de classificação dos genótipos do VHC tem sido proposto.

A comparação das sequiências da região NS5 (que representa provavelmente uma atividade RNA-polimerase-RNA-dependente, que é necessária durante a replicação do VHC) de variantes de diferentes partes do mundo foram avaliadas e 
estabeleceu-se que as seqüências genômicas com similaridade menor que $72 \%$ com alguma sequiência conhecida evidencia a existência de um novo tipo viral. (Figura 1)

FIGURA 1 - ESTRUTURA DO GENOMA DO VÍRUS DA HEPATITE C

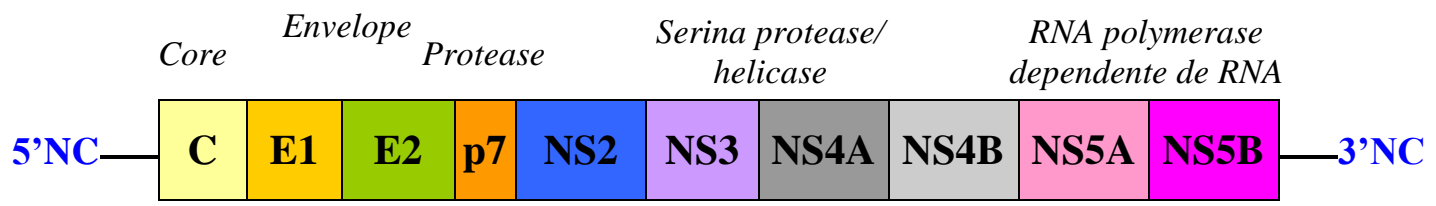

MODIFICADO DE: Cavalheiro, NP. Análise dos sorotipos do VHC identificados em pacientes da cidade de São Paulo, através de método imunoenzimático [Dissertação de Mestrado];1999.

Entre aqueles considerados de um mesmo subgrupo (subtipo) o grau de similaridade varia entre 75 e $86 \%$ (média $80 \%$ ); os isolados individuais, para cada um dos grupos apresentados, tem $88 \%$ de similaridade.

Os tipos do VHC devem ser identificados por numerais arábicos para evitar confusão com nomenclaturas anteriores, para os subtipos a indicação se faz por letra minúscula, ambos por ordem de descoberta.

Seis genótipos $(1,2,3,4,5,6)$ apresentando entre 2 e 3 subtipos (a,b,c) para alguns destes genótipos têm sido sugeridos como padrão de nomenclatura para os VHC.

As variantes descobertas no Vietnã, Tailândia, Burma e Indonésia, inicialmente classificadas como genótipos 7, 8, 9, 10 e 11, foram reclassificadas pois análises complementares sugeriram que os grupos $7,8,9$ e 11 deveriam ser classificados dentro do genótipo 6a e o tipo 10 agrupado dentro do tipo $3 a$.

A Figura 2 mostra a árvore filogenética do VHC com seus tipos e subtipos representados. 


\section{FIGURA 2 - ÁRVORE FILOGENÉTICA DO VÍRUS DA HEPATITE C MOSTRANDO OS TIPOS DE 1 AO 6 E SEUS SUBTIPOS}

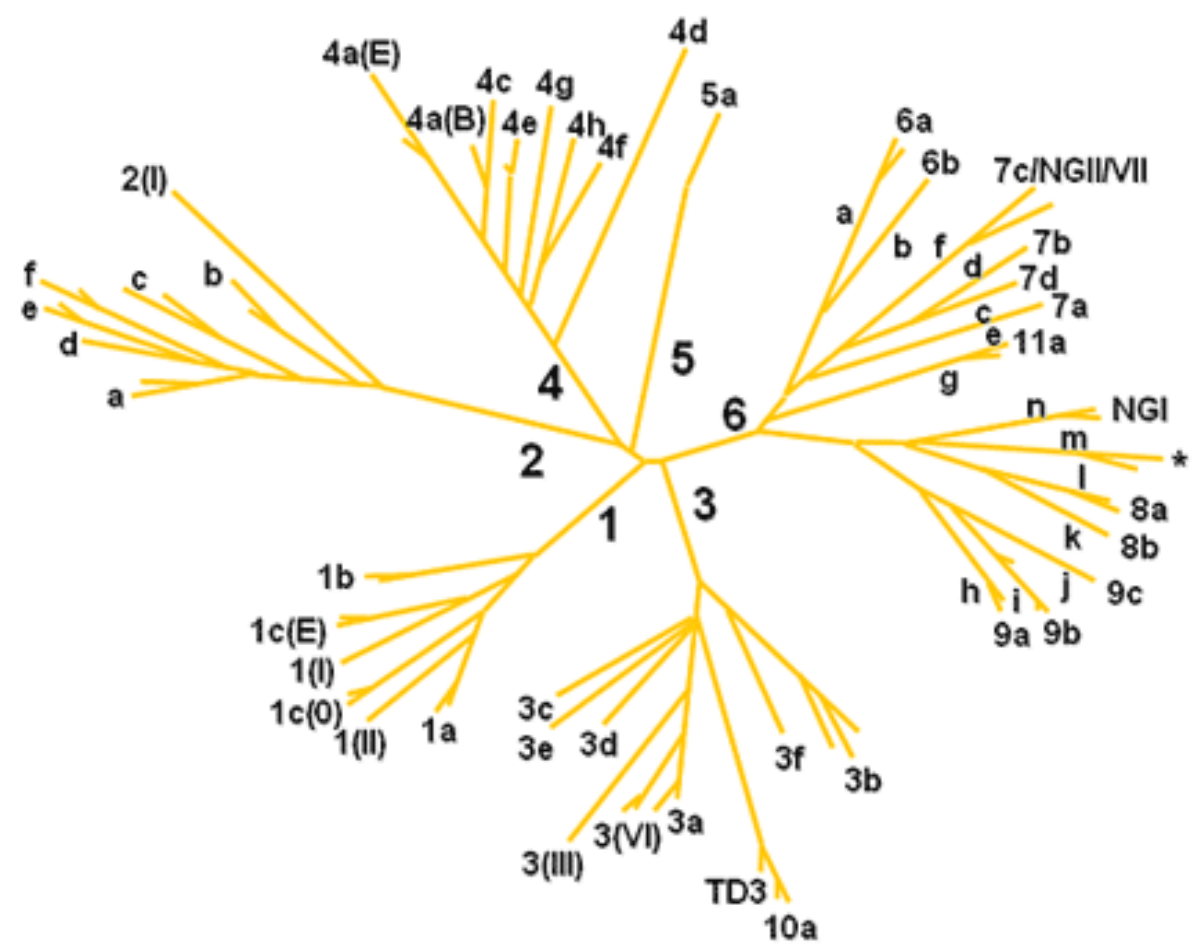

NOTA: Árvore filogenética do vírus VHC mostrando sua complexidade genética.

Observa-se nela diferentes categorias e os seus correspondentes graus de similaridade genômicas expressados em percentagens (\%); Tipos ou Espécies: 6669\%; Subtipo: 77-80\%; Isolado: 91-95\%; Quasispécies > 98\%.

O termo quasispécie representa a heterogeneidade do VHC ocorrida em um mesmo hospedeiro durante o curso da infecção e sugere importantes implicações patobiológicas.

A natureza de quasispécie do VHC provavelmente constitui um dos mecanismos pelo qual o VHC promove um escape imunológico e estabelece a infecção crônica no hospedeiro e, por outro lado, também pode estar influenciando os resultados da terapia com Interferon em pacientes infectados pelo VHC. As seqüências dos genomas do VHC estão agora disponíveis para todos os seis tipos e os diversos subtipos para sua avaliação laboratorial em todo o mundo. $(69,85,86)$ 


\subsection{Epidemiologia}

A distribuição do VHC é mundial. Embora a OMS acredite que atualmente 170 milhões de pessoas ao redor do mundo tenham a infecção por esse vírus e se encontram em risco de adquirir carcinoma hepatocelular. (1)

É certo que existem áreas que apresentam uma maior prevalência na população geral, ao redor de 2 a $4 \%$ da população mundial, com variações regionais. Estudos feitos em populações, como a americana, mostram uma prevalência de aproximadamente 1,8\% com 28.000 novas infecções por ano em 1995. (9)

A OMS, no seu mapa epidemiológico mundial, mostra que a Bolívia seria na América do Sul o país com maior prevalência de infecção pelo VHC, tendo mais de 10\% da população infectada, dados de 2001 (1), enquanto em nível mundial a maior prevalência seria a da população egípcia que alcança prevalência por regiões de até $40 \%$ da população geral infectada, em decorrência das campanhas de tratamento contra a esquistossomose feita na década dos 20 com Hycanthone. (87) 


\section{TABELA 1 - PREVALÊNCIA ESTIMADA DO VHC E NÚMERO DE PESSOAS INFECTADAS POR DADOS DA OMS}

\begin{tabular}{lcc|c|c}
\hline \multicolumn{1}{c|}{ REGIÃO } & $\begin{array}{c}\text { POPULAÇÃ̃O } \\
\text { TOTAL } \\
\text { (Milhões) }\end{array}$ & $\begin{array}{c}\text { PREVALÊNCIA } \\
\text { HCV } \\
(\%)\end{array}$ & $\begin{array}{c}\text { POPULAÇÃO } \\
\text { INFECTADA } \\
\text { (Milhões) }\end{array}$ & OMS $^{(*)}$ \\
\hline África & 602 & 5,3 & 31,9 & 12 \\
Américas & 785 & 1,7 & 13,1 & 7 \\
$\begin{array}{l}\text { Leste } \\
\text { Mediterrâneo }\end{array}$ & 466 & 4,6 & 21,3 & 7 \\
Europa & 858 & 1,03 & 8,9 & 19 \\
$\begin{array}{l}\text { Sudeste } \\
\text { Asiático }\end{array}$ & 1500 & 2,1 & 32,3 & 3 \\
Pacífico Oeste & 1600 & 3,9 & 62,2 & 11 \\
TOTAL & 5811 & 3,1 & 169,7 & 57 \\
\hline
\end{tabular}

FONTE: Weekly Epidemiological Record, n 49, December 1999, WHO.

(*) Número de países por região OMS cujos dados não são disponíveis.

No Brasil, infelizmente, ainda não existem dados de âmbito nacional da população, mas estudos feitos em doadores de sangue mostram uma prevalência entre 0,84 e $3,4 \%$ em diferentes partes do Brasil. (18)

No estado de São Paulo, a prevalência do VHC entre doadores de sangue foi de 0,84\% (18) e na população geral da cidade de São Paulo um estudo desenhado usando um método indutivo de inferências estatísticas preditivas através de amostragem randomizada estratificada por sexo, idade e região de residência, a prevalência foi calculada em $1,42 \%(0,70 \%-2,12 \%)$. (88)

Nas populações HIV-1 positivas as cifras de prevalência de co-infecção VHC são variáveis. 
Uma avaliação da presença de marcadores sorológicos de hepatite B e sorologia para hepatite $\mathrm{C}$ em pacientes com infecção pelo HIV da cidade de Aquitaine (sudoeste da França) entre os anos 1991-1994 mostrou que entre 1.935 pacientes HIV positivos, a presença de anticorpos contra o VHC (detectada com ELISA de II geração e RIBA) foi de 42,5\%. A prevalência de anticorpos anti-VHC foi $86,1 \%$ em pacientes com infecção HIV adquirida por transfusão e 7,3\% (66/89) naqueles com infecção adquirida pela via sexual. (2)

Diferentes publicações têm sido feitas avaliando a prevalência do VHC em populações infectadas pelo HIV.

\section{TABELA 2 - PREVALENCIA DE VHC EM PACIENTES INFECTADOS POR HIV}

\begin{tabular}{|c|c|c|c|c|}
\hline ANO & $\begin{array}{c}\text { NÚMERO } \\
\text { DE } \\
\text { PACIENTES } \\
\end{array}$ & LOCAL & $\begin{array}{c}\text { POPULAÇÃO } \\
\text { ESTUDADA }\end{array}$ & $\begin{array}{c}\text { PREVALENNCIA } \\
\text { HCV } \\
(\%) \\
\end{array}$ \\
\hline \multicolumn{5}{|l|}{ EUROPA } \\
\hline 2000 & 125 & UK & Hemofílicos & $98 \%$ \\
\hline 1998 & 3048 & Europa & $\begin{array}{c}43 \% \mathrm{HSH}^{(1)} \\
27 \% \mathrm{IVUD}^{(2)} \\
2,4 \% \text { transfusão }\end{array}$ & $\begin{array}{l}\text { 33\% (HSH 6\%; } \\
\text { IVUD 91\%; } \\
\text { transfusão 59\%) }\end{array}$ \\
\hline 1999 & 204 & Espanha & $\begin{array}{c}77 \% \text { masculino } \\
26 \% \text { HSH } \\
61 \% \text { IVUD }\end{array}$ & $57 \%$ \\
\hline 2000 & 3111 & Suécia & $\begin{array}{c}65,6 \% \\
\text { masculino } \\
33 \% \text { HSH } \\
35,6 \% \text { IVUD }\end{array}$ & $\begin{array}{c}37,2 \%(\mathrm{HSH} \\
3,7 \% ; \text { IVUD } \\
\quad 87,7 \%)\end{array}$ \\
\hline 2000 & 394 & Holanda & $\begin{array}{c}80 \% \text { masculino } \\
58 \% \mathrm{HSH} \\
9 \% \text { IVUD }\end{array}$ & $\begin{array}{c}15 \%(\text { HSH } 2,6 \% \\
\text { IVUD } 97 \% \text { ) }\end{array}$ \\
\hline
\end{tabular}


conclusão

\begin{tabular}{|c|c|c|c|c|}
\hline ANO & \begin{tabular}{|c|} 
NÚMERO \\
DE \\
PACIENTES \\
\end{tabular} & LOCAL & $\begin{array}{c}\text { POPULAÇÃO } \\
\text { ESTUDADA }\end{array}$ & $\begin{array}{c}\text { PREVALÊNCIA } \\
\text { HCV } \\
(\%) \\
\end{array}$ \\
\hline \multicolumn{5}{|c|}{ NORTEAMÉRICA } \\
\hline 1991 & 101 & $\begin{array}{l}\text { Sacramento, } \\
\text { EUA }\end{array}$ & $\begin{array}{c}91 \% \text { masculino } \\
7 \% \text { transfusão } \\
30 \% \text { IVUD } \\
75 \% \\
\text { promiscuidade } \\
\text { sexual }\end{array}$ & $\begin{array}{l}7 \% \text { (IVUD 16\%; } \\
\text { transfusão 29\%) }\end{array}$ \\
\hline 1994 & 512 & $\begin{array}{l}\text { São } \\
\text { Francisco, } \\
\text { EUA }\end{array}$ & $\begin{array}{c}98 \% \text { masculino } \\
83 \% \text { HSH } \\
7 \% \text { IVUD } \\
8,5 \% \text { transfusão }\end{array}$ & $\begin{array}{c}\text { 14\% (HSH 11,7\%; } \\
\text { IVUD } 40 \% ; \\
\text { transfusão } 31,6 \%)\end{array}$ \\
\hline 1998 & 934 & $\begin{array}{l}\text { Nova } \\
\text { Iorque, } \\
\text { EUA }\end{array}$ & $\begin{array}{c}4 \% \text { transfusão } \\
37 \% \text { HSH } \\
37 \% \text { IVUD }\end{array}$ & $\begin{array}{l}\text { 40\% (HSH 12\%; } \\
\text { IVUD } 81 \% \text { m; } \\
\text { transfusão } 78 \% \text { ) }\end{array}$ \\
\hline 1997 & 587 & $\begin{array}{l}\text { Hawai, } \\
\text { EUA }\end{array}$ & $\begin{array}{c}93,2 \% \\
\text { masculino } \\
75 \% \text { HSH } \\
14 \% \text { IVUD }\end{array}$ & $\begin{array}{c}\text { 17\% (HSH 6,6\%; } \\
\text { IVUD 95\%) }\end{array}$ \\
\hline 1998 & 511 & NIH, EUA & $\begin{array}{c}\text { Todos } \\
\text { femininos }\end{array}$ & $32 \%$ \\
\hline 1999 & 3.134 & $\begin{array}{l}\text { Texas, } \\
\text { EUA }\end{array}$ & $\begin{array}{l}\text { Pacientes e } \\
\text { prisioneiros }\end{array}$ & $43 \%$ \\
\hline 1999 & 350 & $\begin{array}{l}\text { Geórgia, } \\
\text { EUA }\end{array}$ & $\begin{array}{c}98,6 \% \\
\text { masculino } \\
47 \% \text { HSH } \\
20 \% \text { IVUD }\end{array}$ & $\begin{array}{l}33 \% \text { (HSH 14\%; } \\
\text { IVUD 83\%) }\end{array}$ \\
\hline 1993 & 226 & $\begin{array}{l}\text { Toronto, } \\
\text { Canadá }\end{array}$ & $\begin{array}{c}94 \% \text { masculino } \\
44 \% \text { HSH } \\
61 \% \text { dos VHC+ } \\
\text { era IVUD e } \\
\text { transfusão } 22 \%\end{array}$ & $8 \%$ \\
\hline 1993 & 382 & EUA & Hemofílicos & $98 \%$ \\
\hline
\end{tabular}

FONTE: Mohsen, Easternbrook, Taylor et al. Hepatitis C and HIV-1 co-infection. Gut 51:601-8,2002.

(1) HSH: Homens que Fazem Sexo com Homens

(2) IVUD: Usuários de Drogas Intravenosas

Nos Estados Unidos, no momento, aproximadamente um a dois milhões de americanos possui a infecção pelo HIV. A AIDS transformou-se na terceira causa de 
mortalidade entre as mulheres americanas entre 25 e 44 anos e atualmente é a primeira causa de morte entre homens brancos na mesma faixa etária. Após a infecção pelo HIV, os pacientes tornam-se susceptíveis a uma variedade de processos hepáticos relacionados à imunossupressão ou associados a fatores de risco como homossexualidade e uso de drogas intravenosas. As infecções oportunistas intrahepáticas e neoplasias são observadas em 33 a $68 \%$ de pacientes com AIDS na necropsia e, mais especificamente, a doença hepática na AIDS apresenta-se de várias maneiras que incluem febre, dor no quadrante superior direito e hepatomegalia. Mais de $90 \%$ dos pacientes com AIDS têm anormalidades das enzimas hepáticas no momento da apresentação. Um fígado alargado pode ser detectado em 60 a $73 \%$ dos casos e na autópsia, 84\% tem hepatomegalia. Quando o fígado é analisado histopatologicamente, são encontradas anormalidades em quase todos os pacientes. $(7,8)$

Desde a sua identificação em 1989, o enorme potencial patogênico do VHC foi reconhecido. Este vírus RNA infecta comumente os portadores do HIV. A incidência de co-infecção é grande em usuários de drogas intravenosas, nos receptores de transfusões sangüíneas e hemofílicos. Aproximadamente $80-90 \%$ de pacientes que adquiriram o HIV através de uso de drogas intravenosas e dos hemofílicos são coinfectados com o VHC. Por outro lado, entre homossexuais masculinos a incidência é de $8-15 \%$. As evidências sugerem que o HIV interage com o VHC influenciando o curso e a transmissão da doença. O risco de transmissão sexual aparenta ser baixo, mas Eyuster e col. revelaram que a transmissão masculino-feminina é cinco vezes mais eficiente quando o HIV encontra-se presente. (3) 
Programas de intervenção em populações de risco têm sido de interesse no intuito de diminuir a taxa de prevalência tanto VHC quanto HIV, mas sem mostrar resultados consistentes. $(21,74,78)$

Transmissão materno-fetal VHC-HIV tem sido também tema de interesse para a saúde pública em geral. Na cidade de Bergamo, na Itália foi conduzido um estudo prospectivo para avaliar a prevalência e curso natural da infecção crônica pelo VHC em uma população de 15.250 mulheres grávidas. A presença de VHC, HIV e dosagem de ALT foi acompanhada durante o primeiro mês e o terceiro trimestre de gravidez e 6 meses depois do parto. Foi encontrada positividade anti-VHC em 370 casos $(2,4 \%), 72 \%$ dos quais a positividade para o VHC-RNA também foi evidenciada. A proporção de mulheres com elevação das transaminases decresce de $56,4 \%$ no primeiro exame para 7,4\% no último trimestre. Após o parto observou-se aumento $(54,5 \%)$ sem alterações importantes. A proporção de crianças anti-VHC e VHC-RNA foi de 5,1\% após um ano e todas com o mesmo genótipo que a mãe. A taxa de transmissão VHC não foi afetada pelo tipo de parto, alimentação e pelo estado HIV da mãe. Os resultados deste estudo confirmam os de estudos menores quanto a prevalência em gestantes e sugerem fortemente a possibilidade (provavelmente imunomediada) de um percurso favorável da necrose celular em mulheres anti-VHC positivas. (72)

\subsection{Relevância da co-infecção HIV-VHC}

A influência recíproca dos vírus HIV-VHC devido a padrões de transmissão comuns, frequientemente ocorre em pacientes hemofílicos e usuários de drogas 
intravenosas. Esta co-influência foi estabelecida antes inclusive da era da terapia antirretroviral altamente ativa (HAART) e continua a ser um tópico de debate, a questão de qual dos vírus se deve tratar primeiro. (98)

Um estudo realizado no Hospital Royal Victoria de Quebec, Canadá, avaliou através de um estudo retrospectivo de coortes qual o impacto da terapia antirretroviral altamente ativa (HAART) na progressão da infecção pelo HIV em pacientes co-infectados com o VHC. Entre 125 pacientes VHC positivos e 1.076 pacientes VHC negativos foram estudados, sendo $83 \%$ dos pacientes VHC positivos usuários de drogas intravenosas. Os pacientes VHC positivos não experimentaram um beneficio claro da HAART.

Os Hazard Ratios ajustados (HRs) de infecção oportunista, morte e internação foram 0,74 (95\% IC: 0,31-1,78), 1,78 (95\% IC: 0,59-5,37) e 2,1 (95\% IC: 0,90-4,90) respectivamente, comparadas as eras pós-HAART com a pré-HAART. Em contraste com os VHC negativos que experimentaram uma redução em todas as variáveis analisadas, sendo os HRs equivalentes de: 0,49 (95\% IC: 0,37-0,64); 0,28 (95\% IC: 0,19-0,41) e 0,51 (95\% IC: $0,38-0,67)$. Os pacientes VHC positivos permaneceram com um risco incrementado de morte e internação na era pós-HAART inclusive fazendo ajustes adicionais das doses e acompanhamento de CD4 e carga viral HIV. As mortes neste grupo foram principalmente por doenças não-definidoras de AIDS e por complicações derivadas do uso de drogas intravenosas. (96)

$\mathrm{O}$ vírus da hepatite $\mathrm{C}$ emergiu como a causa da segunda maior epidemia viral depois do HIV nas duas últimas décadas e a co-infecção do HIV e o VHC representa um crescente problema para o futuro. Aproximadamente $3 \%$ da população mundial se estima como infectada e a viremia persiste em $80 \%$ dos casos. É reconhecida 
como uma das principais causadoras de doença hepática sendo a principal causadora de mortalidade devido a complicações hepáticas. Nos Estados Unidos a co-infecção HIV-VHC apresenta um problema crescente para o futuro. Estima-se que 240.000 indivíduos têm a co-infecção. (92)

A progressão da hepatite crônica relacionada ao VHC em pacientes HIV claramente mostra uma maior taxa de progressão para a fibrose. Um estudo dirigido no Hospital Universitário de Cadiz, Espanha, visou avaliar os fatores associados à progressão de variáveis histológicas comparadas com parâmetros demográficos, carga viral VHC e genótipo. Carga viral HIV, CD4+ e resposta a HAART. Pacientes co-infectados HIV-VHC mostraram uma carga viral VHC significantemente alta, fibrose mais avançada e uma maior progressão de fibrose hepática que os pacientes não-infectados pelo HIV. A resposta imune induzida pela HAART não influenciou esta progressão. Concluíram que os pacientes HIV-VHC, principalmente aqueles com uma carga viral VHC alta e estado de imunossupressão, têm um maior índice de progressão de fibrose, e um efeito independente da resposta imune a HAART não foi evidente. (94)

Desde a introdução da terapia altamente eficaz (HAART), as taxas de morte atribuível à hepatite $\mathrm{C}$ crônica mostram-se mais evidentes. Estudos recentes mostram que o VHC é a principal causa de morte nos pacientes com co-infecção HIV-VHC, sendo que a doença hepática leva a morte 50\% desses indivíduos. (79)

Nos países desenvolvidos, o HIV-1 transformou-se de uma doença que foi quase uniformemente fatal em uma doença crônica que pode levar a infecções oportunistas. Os pacientes imunossuprimidos têm uma série de manifestações hepáticas: desde problemas virais, fúngicos, bacterianos e até por protozoários, com variadas 
manifestações, geralmente febre, dor no quadrante superior direito e hepatomegalia. $(30,36,40)$

A infecção pelo vírus de hepatite $\mathrm{C}$ em aproximadamente $50 \%$ dos pacientes imunocompetentes irá produzir cirrose depois de 20 anos, sendo que $15 \%$ desses poderiam evoluir para hepatocarcinoma. A co-infecção com o HIV-1 altera o curso natural da doença causada pelo VHC de uma maneira significativa. Ao contrário que no VHB onde o dano será principalmente devido à ação mediada por imunidade, no VHC a ação se deve fundamentalmente a ação citopática direta, sendo que o processo de deterioração hepática encontra-se mais acelerado. Há estudos que mostram que os pacientes com HIV-1 têm uma viremia do VHC dez vezes maior que os imunocompetentes. $\mathrm{O}$ significado patogênico disso não é claro devido à escassa correlação entre a carga viral plasmática e o dano hepatocelular, mas a maioria dos estudos sugere que a co-infecção pelo HIV acelera o processo de dano hepático pelo VHC. $(1,39,49)$

Na região sudeste de Yunnan, na China, lugar chave para o tráfico de drogas e avanço da infecção pelo HIV desde o Leste de Yunnan até Laos ao Sudeste da China, para investigar a prevalência da infecção pelo HIV-1 e co-infecção pelo VHC entre os usuários de drogas, três coortes de 285 dependentes (242 de usuários intravenosos e 43 usuários de drogas orais) morando nas cidades de Geiju e Kaiyuan e o país de Yanshan foram estudados.

HIV e VHC foram identificados por ELISA e/ou PCR e dados de idade, sexo, fatores de risco, história de uso de drogas, emprego, etnia e estado marital foram estudados, sendo a prevalência global do HIV-1 de 71,9\%. A porcentagem de coinfecção VHC entre 138 IVU foi de 99,3\%. Sendo que a grande maioria dos IVU 
eram jovens entre $20-35$ anos $(86,7 \%)$ e da etnia Han $(75,9 \%)$, o que sugere que o HIV-1 não se encontra confinado as etnias não Han.

A prevalência feminina $(81,2 \%)$ foi significativamente maior que em homens IVU $(68,2 \%)$. E a prevalência de HIV-1 naqueles usuários de menos de 1 ano foi de $68,4 \% .(80)$

No Brasil existem também estudos interessantes de co-infecção VHC-HIV.

Na Casa da AIDS foi conduzido um estudo retrospectivo de análise de prontuários médicos com o objetivo de avaliar a soroprevalência e fatores de risco associados à infecção pelo VHC em pacientes HIV soropositivos.

Foram analisados os prontuários médicos de 1.457 pacientes, todos eles testados para infecção VHC por ELISA de terceira geração. Quando possível, os pacientes eram testados também para PCR-VHC.

A soroprevalência anti-VHC nesta população foi estimada em 17,7\%, sendo esta população composta por usuários de drogas intravenosas $(58,5 \%)$, parceiros de pacientes HIV 16,3\%, 8,9\% homens que fazem sexo com homens, tendo como conclusão que, mesmo sendo o uso de drogas intravenosas o fator de risco mais evidente para co-infecção, a transmissão sexual aparentemente contribuiria para a alta soroprevalência neste grupo de pacientes. (18)

\subsection{Modos de transmissão}

$\mathrm{O}$ vírus de hepatite $\mathrm{C}$ foi considerado tradicionalmente um vírus relacionado à transmissão sangüínea através do uso de sangue ou produtos derivados de sangue contaminados, mais isso foi mudando através do tempo; com o desenvolvimento de 
técnicas para sua identificação, o risco remanescente de transfusão chegou a praticamente zero e atualmente o principal fator de risco nos países desenvolvidos é o uso ilegal de drogas intravenosas. (12)

Em geral, um fator de risco potencial pode ser estabelecido em aproximadamente $90 \%$ dos casos de infecção pelo VHC. (9)

Estudos tentando mostrar a eficácia da transmissão vertical tem reportado resultados conflitantes, provavelmente devido aos diferentes fatores de risco envolvidos nas populações maternas estudadas ou a metodologias diferentes não permitindo chegar a conclusões claras devido aos múltiplos fatores de confusão, por exemplo, a co-infecção com HIV-1, elevada carga viral HIV-1, viremia VHC, presença vaginal do vírus VHC, gênero feminino do feto, etc., têm sido associados como fatores de risco para transmissão vertical do VHC. $(10,59)$

A transmissão sexual, que inicialmente foi associada à transmissão do VHC, não tem sido mostrada como um mecanismo eficaz de transmissão no paciente imunocompetente. Porém, aparentemente os riscos aumentam no paciente portador do HIV.

Na França, estudos em um grupo na cidade de Aquitaine mostraram que a prevalência de anticorpos VHC em pacientes HIV positivo foi $86,1 \%$ em pacientes com infecção adquirida por via intravenosa e 7,3\% entre aqueles que provavelmente contraíram a infecção por via sexual. (2)

Estudos feitos em população de prisões na Irlanda mostram que mais de 1/3 da população geral de internos e mais de $80 \%$ dos presos que usaram drogas intravenosas são positivos ao VHC, o que é similar ao encontrado em população de presos na Grécia, e maior que os números encontrados na Escócia e Austrália (78). 
Tem sido associado também como fator de risco o uso de piercings, tatuagens, acupuntura, outras formas de contaminação por artigos ou equipamentos contaminados. (9)

Existe um relato interessante de transmissão do vírus adquirido por um anestesiologista que provavelmente o transmitiu a 5 dos seus pacientes através de microlesões produzidas durante os procedimentos normais durante uma cirurgia rotineira. (19)

\subsection{Terapia antiviral em pacientes co-infectados}

A infecção com o vírus da hepatite C ou HIV são comuns nos pacientes hemofílicos devido à transmissão através dos fatores de coagulação. Recentemente a HAART melhorou marcadamente a viremia e parâmetros imunológicos em pacientes infectados pelo HIV. Os relatos consideram interações entre as infecções virais, sistema imune e terapia antirretroviral. Um estudo agrupou um total de 130 pacientes de acordo com o tipo de viremia (VHC, HIV, os dois ou nenhum deles). Estes grupos foram comparados com 30 pacientes pareados por idade em relação a parâmetros como carga viral e imunológicos. Em pacientes com co-infecção VHC-HIV as cargas virais se correlacionaram inversamente com os linfócitos-B periféricos e a contagem de CD4+. A HAART reduziu respectivamente os níveis de ambos os vírus no sangue. Desse grupo de pacientes, a HAART eliminou o VHC em 2/25 casos. (31)

Existem evidências de eliminação de outros vírus hepatotrópicos (vírus de hepatite G, por exemplo) pelo uso de terapia antirretroviral (HAART), isto relacionado diretamente com a melhora de função imunológica. (43) 
Relatam-se também casos nos quais o início de HAART apresentou resultados negativos, tais como anemia aplásica (54), hiperglicemia em pacientes em uso de inibidores da protease (81), hepatotoxicidade associada ao uso dos 6 inibidores da protease atualmente aprovados pela FDA, principalmente com a dose de $600 \mathrm{mg}$ de Ritonavir de dose total (600 mg bid ou $400 \mathrm{mg}$ bid associado a Saquinavir), o que levou este esquema a ser substituído pelo de dose baixa de Ritonavir combinado como "booster" seja com Lopinavir ou Indinavir, sendo esta hepatotoxicidade potencializada pela presença seja do VHB quanto do VHC, recomendando-se que não sendo contra-indicado o uso de inibidores da protease nestes pacientes, eles devem ser monitorados de perto $(61,82)$. Hepatotoxicidade com NNRTI tem sido menos relatada, mas existem relatos de casos isolados de pacientes com Nevirapina e Efavirenz que apresentaram episódio de hepatotoxicidade enquanto usavam regime HAART contendo tais medicamentos, estando infectados com VHC (37). Estudo feito no Hospital Carlos II (Madrid, Espanha) mostrou que entre os pacientes que usaram esquemas HAART contendo NNRTI o dano hepático foi observado com uma freqüência três vezes maior entre aqueles que usaram Nevirapina do que entre aqueles usando Efavirenz, sendo a co-infecção com o HIV, abuso do álcool e gênero feminino, fatores que aumentaram o risco de desenvolver hepatotoxicidade com ambas as drogas. (84)

Provavelmente a hepatotoxicidade poderia ser reduzida se os pacientes fossem previamente tratados da infecção pelo VHC, sendo que ele já é um fator independente de hepatotoxicidade relacionada ao uso de HAART. No estudo dirigido na Universidade Vita-Alute de San Rafael (Milão, Itália) os dados de um estudo comparativo entre pacientes co-infectados que foram tratados versus aqueles não 
tratados em esquema habitual de Interferon e Ribavirina, o tratamento prévio da hepatite crônica ativa produzida pelo vírus da hepatite $\mathrm{C}$ na co-infecção com HIV seria um fator independente associado a diminuição da hepatotoxicidade severa como resultado do esquema HAART. Os autores confirmam também que os níveis de ALT são um importante fator de prognóstico para um dano hepático incrementado durante a terapia antirretroviral. (83) 


\section{3 - OBJETIVOS}

Descrever as características epidemiológicas, clínicas e laboratoriais de uma população de co-infectados HIV-VHC estudada pelo do tipo de terapia antirretroviral recebida. 


\section{4 - CASUÍSTICA E MÉTODOS}

\subsection{Local}

Foram avaliados os prontuários dos pacientes em acompanhamento no Núcleo de Extensão para Atendimento de Pacientes com HIV/AIDS (Casa da AIDS) da Divisão de Clínica de Moléstias Infecciosas e Parasitárias do Hospital das Clínicas da Faculdade de Medicina da Universidade de São Paulo. Este ambulatório foi criado para atendimento exclusivo de doentes com AIDS e está subordinado à Divisão de Clínica de Moléstias Infecciosas e Parasitárias do Hospital das Clínicas da Faculdade de Medicina da Universidade de São Paulo, atendendo uma população de quase 4.000 (quatro mil) pacientes portadores desta infecção.

O Núcleo de Extensão para Atendimento de Pacientes com HIV/AIDS (Casa da AIDS) funciona na Rua Frei Caneca, no Bairro de Cerqueira César, no centro da cidade de São Paulo, em área física diferente do Hospital das Clínicas desde o ano de 1996, para onde foi mudado do antigo prédio da Rua Cardeal Arcoverde em Pinheiros aonde começou no ano de 1994. O serviço atende de segunda a sexta, das $08 \mathrm{~h}$ às $20 \mathrm{~h}$. 


\subsection{Desenho do Estudo}

Foi desenvolvido um estudo retrospectivo, de tipo descritivo, usando a metodologia de revisão de prontuários, cujos participantes foram pacientes portadores do vírus HIV que apresentaram co-infecção com o vírus de hepatite $\mathrm{C}$ e que se encontravam em acompanhamento na Casa da AIDS.

Visando respeitar os aspectos éticos, o projeto foi submetido a parecer e aprovado tanto pela Comissão de Investigação do Departamento de Doenças Infecciosas do Hospital das Clínicas no dia 22/08/2001, quanto pela Comissão de Ética e Pesquisa do Hospital das Clínicas - CAPPesq em 10/10/2001.

Sendo um estudo que prevê unicamente a revisão de prontuários, foi dispensada a necessidade de submeter Termo de Consentimento Livre e Esclarecido.

Os prontuários estudados eram provenientes de uma listagem emitida no dia 03/09/2001 que incluía todos os prontuários ativos nesse momento, sendo considerado como prontuário ativo todo aquele que tivesse sido atendido em consulta médica pelo menos uma vez durante o último ano.

\subsection{Definição dos casos e critérios de exclusão}

Foram revisados os 3.512 prontuários ativos com o intuito de estabelecer uma base de dados de co-infecção, baseada na presença de positividade ao ELISA-HIV, Western Blot e ELISA-HCV.

Os 3.512 pacientes apresentavam positividade ao ELISA-HIV e Western Blot, sendo que 435 não tinham sido avaliados para presença de ELISA-HCV. Nos 
restantes 3.077 foi testada a presença de anticorpos para o VHC, onde para 468 pacientes foram localizados pelo menos uma reação positiva para a presença de anticorpos para VHC. Para 2.069 pacientes a sorologia foi negativa e finalmente, para 7 pacientes a reação de ELISA mostrou-se indeterminada.

Os 468 pacientes restantes foram separados de acordo com a realização ou não de biopsia hepática, havendo sido este procedimento realizado em 121 pacientes. Os pacientes assim identificados foram divididos para análise em dois grupos: Grupo 1 e Grupo 2.

Foi considerado caso do Grupo 1-CIP todo aquele paciente co-infectado VHCHIV que reunisse os seguintes critérios: em acompanhamento regular na Casa da AIDS, que tenha recebido por pelo menos seis meses esquema antirretroviral com pelo menos um inibidor da protease e que tenha feito pelo menos uma biopsia hepática durante este período.

Foi considerado caso do Grupo 2-SIP todo aquele paciente co-infectado HIVVHC em acompanhamento regular na Casa da AIDS, que tenha recebido por pelo menos seis meses esquema antirretroviral sem conter inibidores da protease e que tenha feito pelo menos uma biopsia hepática durante este período. Ficando claro que os regimes terapêuticos não foram alterados durante o tratamento.

Foram considerados critérios de exclusão do estudo:

- pacientes com dados incompletos ou que não apresentassem no momento de ingresso no trabalho, testes confirmatórios da infecção pelos vírus HIV e VHC; 
- pacientes que apresentaram história clínica com letras ilegíveis ou com caracteres que dificultassem a leitura dos mesmos;

- pacientes com dados que apresentaram co-infecção com outros tipos de hepatites virais ou doenças auto-imunes;

- pacientes que já haviam recebido terapia antiviral para o vírus da hepatite C.

Um total de 10 pacientes foi excluído por ter apresentado sorologia positiva para o VHB, por não fazer uso de antirretrovirais ou ter feito uso de Interferon como tratamento para o VHC.

Definições do estudo:

- infecção pelo HIV: presença de positividade ao ELISA confirmada pelo Western-Blot;

- infecção pelo VHC: positividade ao PCR para RNA-VHC;

- co-infecção VHC-HIV: positividade para ambos os agentes.

\subsection{Procedimentos Laboratoriais}

Os exames laboratoriais foram realizados no Laboratório Central do Hospital das Clínicas da Faculdade de Medicina da Universidade de São Paulo, no Laboratório da Fundação Pró-Sangue-Hemocentro de São Paulo, no Laboratório de Investigação Médica em Hepatites por Vírus da FMUSP (LIM-47) e em laboratórios particulares. 


\subsection{Variáveis analisadas}

Uma vez identificados os prontuários dos pacientes co-infectados pelos vírus HIV-VHC acompanhados na Casa da AIDS, foi efetuada a coleta de dados dos seguintes parâmetros:

\section{Dados demográficos:}

- Gênero: masculino ou feminino;

- Idade: determinada em anos;

- Cor: definido de acordo ao dado coletado pelo médico em atendimento;

- Ocupação: dividida de acordo com o grau de escolaridade, se o paciente apresentou ou não educação superior, sendo esta última universitária ou tecnológica;

- Tempo de diagnóstico da infecção pelo HIV (anos): determinado de acordo com a data da primeira exposição de risco ou primeira determinação de teste de ELISA-HIV positivo;

- Tempo de diagnóstico da infecção pelo VHC (anos): determinado de acordo com a data da primeira exposição de risco ou primeira determinação de teste de ELISA-HCV positivo.

\section{$\underline{\text { II. Dados Clínicos }}$}

- Uso de álcool: foi capturado o dado anotado no prontuário do paciente: nenhum, social ou habitual; 
- Doenças concomitantes: foram divididos para análise segundo o Critério Rio de Janeiro/Caracas de definição de caso de AIDS utilizado pelo Ministério da Saúde, em doenças definidoras ou não definidoras de AIDS;

- Uso de drogas hepatotóxicas: além das usadas no tratamento foram investigadas drogas sabidamente hepatotóxicas de acordo com lista do Anexo 2;

- Sintomas apresentados durante a doença: foram coletados dos prontuários os dados clínicos sugestivos de doença hepática;

- Fonte potencial de infecção pelos HIV-VHC: de acordo com a tabela de recolhimento de dados do Anexo 1, foram coletados os dados dos principais fatores de risco de aquisição das infecções HIV-VHC: sangue, derivados de sangue, órgãos, tecidos de doadores infectados, drogadição intravenosa, uso de artigos potencialmente infectados: medicina tradicional ou folclórica (e.g. acupuntura), tatuagens, "body piercing", contato com pacientes infectados, conduta sexual de risco, transmissão materno-fetal.

\section{Seguimento dos esquemas antirretrovirais utilizados}

- Foi coletada a informação do tipo de esquema antirretroviral administrado ao paciente, sem mudanças pelo tempo mínimo de 6 meses antes da biopsia hepática e dividido entre aqueles esquemas que continham inibidores de protease (Grupo 1) e aqueles que não continham inibidores da protease (Grupo 2).

- Cada biopsia hepática foi analisada separadamente de acordo com o grupo de terapia que o paciente havia recebido nos seis meses anteriores. Não houve casos de mudança de esquema antirretroviral nos casos analisados. 


\section{$\underline{\text { IV. Dados laboratoriais e virológicos }}$}

- Bioquímica hepática (TGO, TGP, GGT, Fosfatase alcalina, Bilirrubina Total e Frações, TP);

- Hematologia: hemograma completo, contagem de plaquetas;

- Contagem de CD4;

- Carga viral para o HIV;

- Biopsia hepática;

- PCR Qualitativo para o vírus da hepatite C. (Anexo 1)

Cada paciente foi alocado a um grupo diferente segundo o esquema antirretroviral que recebeu durante no mínimo seis meses de seguimento, sendo que foram considerados apenas os medicamentos como grupo (não nucleotídeos, nucleotídeos e inibidores da protease).

\subsection{Análise dos dados}

As variáveis qualitativas foram representadas por frequiência absoluta e relativa e as quantitativas por média, desvio padrão (d.p.), mediana, valores mínimo e máximo. 


\section{5 - RESULTADOS}

Foram pesquisados 3.512 prontuários de pacientes em acompanhamento na Casa da AIDS à procura de casos de conversão sorológica para o VHC. Para 435 desses pacientes não foi feita a pesquisa da presença da infecção pelo VHC. Foi possível investigar a presença de sorologia de anticorpos em 3.077 pacientes, dos quais 468 $(15,20 \%)$ apresentaram positividade para o VHC (percentagem de co-infecção).

Foram selecionados 111 pacientes, sendo o critério de escolha o fato de terem sido submetidos à pelo menos uma biopsia hepática durante o seu acompanhamento, dos quais 74 foram tratados com medicamentos inibidores de protease (grupo CIP) e 37 sem inibidores de protease (grupo SIP).

Abaixo estão apresentadas tabelas-resumo dos principais dados analisados, divididos de acordo com o grupo (com ou sem inibidor da protease) no qual foram separados. 


\section{$\underline{\text { I. Dados Gerais }}$}

\section{TABELA 3 - CARACTERÍSTICAS DEMOGRÁFICAS DOS PACIENTES CO-INFECTADOS COM HIV-VHC DE ACORDO COM O TIPO DE TERAPIA ANTIRRETROVIRAL RECEBIDA}

\begin{tabular}{|c|c|c|c|c|}
\hline \multirow{2}{*}{ PARÂMETROS } & \multicolumn{4}{|c|}{ GRUPO } \\
\hline & \multicolumn{2}{|c|}{ CIP } & \multicolumn{2}{|c|}{ SIP } \\
\hline Feminino & 19 & $(25,7)$ & 18 & $(48,6)$ \\
\hline Masculino & 55 & $(74,3)$ & 19 & $(51,4)$ \\
\hline \multicolumn{5}{|l|}{ Raça-n(\%) } \\
\hline Branca & 25 & $(80,6)$ & 17 & $(94,4)$ \\
\hline Negra & 3 & $(9,7)$ & 1 & $(5,6)$ \\
\hline Parda & 3 & $(9,7)$ & 0 & $(0,0)$ \\
\hline \multicolumn{5}{|l|}{ Idade } \\
\hline Média (d.p.) & 41 & $(7,6)$ & 41 & $(8,3)$ \\
\hline Mínimo - Máximo & \multicolumn{2}{|c|}{$26,7-65,4$} & \multicolumn{2}{|c|}{$20,4-61,7$} \\
\hline
\end{tabular}

NOTA: Houve predominância do gênero masculino em ambos os grupos de tratamento correspondendo ao $74,3 \%$ no grupo CIP e 52,4\% no grupo SIP, assim como uma predominância da raça branca com $80,6 \%$ no grupo CIP e $94,4 \%$ no grupo SIP. Não foi possível resgatar o dado raça em 43 pacientes do grupo CIP (58\%). No entanto, no grupo SIP tal dado não foi identificado no prontuário de 19 pacientes (51\%). As idades medidas no momento da realização da primeira biopsia hepática foram em média exatamente iguais em ambos os grupos (41 anos) e o desvio padrão foi maior no grupo SIP (8,3 anos). Houve predominância de não profissionais em ambos os grupos, não atingindo $10 \%$ em nenhum dos dois grupos. 


\section{Antecedentes}

\section{TABELA 4 - FONTE POTENCIAL DE INFECÇÃO IDENTIFICADA NOS PACIENTES CO-INFECTADOS COM HIV-VHC DE ACORDO COM O TIPO DE TERAPIA ANTIRRETROVIRAL RECEBIDA}

\begin{tabular}{l|cc|cc}
\hline \multirow{2}{*}{$\begin{array}{c}\text { FONTE POTENCIAL DE } \\
\text { INFECÇÃO PELOS } \\
\text { VÍRUS HIV-VHC }\end{array}$} & \multicolumn{5}{|c}{ GRUPO } \\
\cline { 2 - 6 } & \multicolumn{3}{|c|}{ CIP } & \multicolumn{3}{c}{ SIP } \\
\hline Pelo menos 1 fator conhecido & 69 & $(\%), 2)$ & 33 & $(89,2)$ \\
Nenhum & 5 & $(6,8)$ & 4 & $(10,8)$ \\
TOTAL & 74 & $(100)$ & 37 & $(100)$
\end{tabular}

NOTA: Foi identificado pelo menos um fator de risco em 93,2\% dos pacientes CIP e em $89,2 \%$ dos pacientes SIP. Os fatores de risco foram considerados comuns para ambas as infecções. Foram pesquisados os seguintes fatores de risco na tabela de recolhimento de dados (Anexo 1): sangue, derivados de sangue, órgãos, tecidos de doadores infectados, drogadição intravenosa, uso de artigos potencialmente infectados (medicina tradicional ou folclórica), tatuagens, "body piercing", contato infectado, conduta sexual de risco e transmissão materno-fetal.

\section{TABELA 5 - CONSUMO DE ÁLCOOL NOS PACIENTES CO-INFECTADOS COM HIV-VHC DE ACORDO COM O TIPO DE TERAPIA ANTIRRETROVIRAL RECEBIDA}

\begin{tabular}{l|cc|cc}
\hline \multirow{2}{*}{\begin{tabular}{c} 
ÚLC DE \\
\cline { 2 - 5 }
\end{tabular}} & \multicolumn{5}{c}{ GRUPO } \\
\cline { 2 - 5 } & \multicolumn{3}{|c|}{ CIP } & \multicolumn{3}{c}{ SIP } \\
\hline Nenhum & 24 & $(36,9)$ & 11 & $(42,3)$ \\
Social & 15 & $(23,1)$ & 8 & $(30,8)$ \\
Habitual & 26 & $(40,0)$ & 7 & $(26,9)$ \\
TOTAL & 65 & $(100,0)$ & 26 & $(100,0)$
\end{tabular}

NOTA: O consumo de álcool foi maior no grupo CIP (Resposta: Habitual 40\%) que no grupo SIP (Resposta: Nenhum 42,3\%). 
TABELA 6 - PRESENÇA DE DOENÇAS DEFINIDORAS DE AIDS ${ }^{(*)}$ NOS PACIENTES CO-INFECTADOS COM HIV-VHC DE ACORDO COM O TIPO DE TERAPIA ANTIRRETROVIRAL RECEBIDA

\begin{tabular}{l|cc|cc}
\hline \multirow{2}{*}{$\begin{array}{c}\text { DOENÇAS } \\
\text { DEFINIDORAS }\end{array}$} & \multicolumn{5}{c}{ GRUPO } \\
\cline { 2 - 6 } & \multicolumn{3}{|c|}{ CIP } & \multicolumn{3}{c}{ SIP } \\
\hline Ausente & $\mathrm{n}$ & $(\%)$ & $\mathrm{n}$ & $(\%)$ \\
Presente & 60 & $(81,1)$ & 32 & $(86,5)$ \\
TOTAL & 14 & $(18,9)$ & 5 & $(13,5)$ \\
& 74 & $(100)$ & 37 & $(100)$
\end{tabular}

NOTA: A grande maioria dos pacientes, tanto do grupo CIP $(81,1 \%)$ quanto do grupo SIP $(86,5 \%)$ não apresentou infecção considerada como doença definidora de AIDS de acordo com o Ministério da Saúde do Brasil.

(*) Critério Rio de Janeiro/Caracas de definição de caso de AIDS (Ministério da Saúde).

\section{TABELA 7 - CONSUMO DE DROGAS HEPATOTÓXICAS NOS PACIENTES CO-INFECTADOS COM HIV-VHC DE ACORDO COM O TIPO DE TERAPIA ANTIRRETROVIRAL RECEBIDA $^{(*)}$}

\begin{tabular}{l|cc|cc}
\hline \multirow{2}{*}{$\begin{array}{l}\text { DROGAS } \\
\text { HEPATOTÓXICAS }\end{array}$} & \multicolumn{5}{c}{ GRUPO } \\
\cline { 2 - 6 } & \multicolumn{3}{|c}{ CIP } & \multicolumn{3}{c}{ SIP } \\
& $\mathrm{n}$ & $(\%)$ & $\mathrm{n}$ & $(\%)$ \\
\hline Ausente & 68 & $(91,9)$ & 32 & $(86,5)$ \\
Presente & 6 & $(8,1)$ & 5 & $(13,5)$ \\
TOTAL & 74 & $(100)$ & 37 & $(100)$
\end{tabular}

NOTA: Uso de drogas consideradas hepatotóxicas durante o acompanhamento clínico foi ausente na maioria dos pacientes do grupo CIP $(91,9 \%)$ quanto do grupo $\operatorname{SIP}(86,5 \%)$.

(*) de acordo com a tabela do Anexo 3. 


\section{Dados Clínicos}

TABELA 8 - PRESENÇA DE SINTOMAS RELACIONADOS À DOENÇA HEPÁTICA NOS PACIENTES CO-INFECTADOS COM HIVVHC DE ACORDO COM O TIPO DE TERAPIA ANTIRRETROVIRAL RECEBIDA

\begin{tabular}{|c|c|c|c|c|}
\hline \multirow{3}{*}{$\begin{array}{c}\text { SINTOMAS } \\
\text { APRESENTADOS } \\
\text { DURANTE A DOENÇA }\end{array}$} & \multicolumn{4}{|c|}{ GRUPO } \\
\hline & \multicolumn{2}{|c|}{ CIP } & \multicolumn{2}{|c|}{ SIP } \\
\hline & $\mathrm{n}$ & $(\%)$ & $\mathrm{n}$ & $(\%)$ \\
\hline Pelo menos 1 sintoma & 12 & $(16,2)$ & 6 & $(16,2)$ \\
\hline Nenhum sintoma & 62 & $(83,8)$ & 31 & $(83,8)$ \\
\hline TOTAL & 74 & $(100)$ & 37 & $(100)$ \\
\hline
\end{tabular}

NOTA: Presença de sintomas relacionados à doença hepática foi pouca em ambos os grupos, sendo exatamente igual em termos percentuais $(16,2 \%)$.

\section{Avaliação Laboratorial}

TABELA 9 - PARÂMETROS BIOQUÍMICOS E VIROLÓGICOS (VALOR MÉDIO, MÍNIMO, MÁXIMO E DESVIO PADRÃO) AVALIADOS NOS PACIENTES CO-INFECTADOS COM HIVVHC DE ACORDO COM O TIPO DE TERAPIA ANTIRRETROVIRAL RECEBIDA

\begin{tabular}{l|c|c}
\hline \multirow{2}{*}{ PARÂMETROS } & \multicolumn{2}{|c}{ GRUPO } \\
\cline { 2 - 3 } & $\begin{array}{c}\text { CIP } \\
\text { Média (d.p.) } \\
\text { Mínimo - Máximo }\end{array}$ & $\begin{array}{c}\text { SIP } \\
\text { Mínimo - Máxim (d.p.) }\end{array}$ \\
\hline \multirow{2}{*}{ Carga Viral HIV } & $53220,3(99443,3)$ & $17946,7(21930,9)$ \\
& $110,0-440000,0$ & $100,0-58000,0$ \\
\hline \multirow{2}{*}{ CD4 } & $362,2(187,5)$ & $378,1(175,3)$ \\
& $54,0-812,0$ & $128,0-673,0$ \\
TGO & $52,1(61,2)$ & $53,2(41,1)$ \\
& $9,0-433,0$ & $10,0-136,0$ \\
\hline \multirow{2}{*}{ TGP } & $60,9(56,4)$ & $71,3(56,2)$ \\
& $7,0-252,0$ & $10,0-261,0$
\end{tabular}


conclusão

\begin{tabular}{|c|c|c|}
\hline \multirow[b]{2}{*}{ PARÂMETROS } & \multicolumn{2}{|c|}{ GRUPO } \\
\hline & $\begin{array}{c}\text { CIP } \\
\text { Média (d.p.) } \\
\text { Mínimo - Máximo }\end{array}$ & $\begin{array}{c}\text { SIP } \\
\text { Média (d.p.) } \\
\text { Mínimo - Máximo }\end{array}$ \\
\hline \multirow{2}{*}{ TGP } & $60,9(56,4)$ & $71,3(56,2)$ \\
\hline & $7,0-252,0$ & $10,0-261,0$ \\
\hline \multirow{2}{*}{ GGT } & $84,4(90,4)$ & $122,9(150,5)$ \\
\hline & $8,0-385,0$ & $9,0-559,0$ \\
\hline \multirow{2}{*}{ Fosfatase Alcalina } & $113,1(54,3)$ & $104,1(34,8)$ \\
\hline & $53,0-330,0$ & $51,0-180,0$ \\
\hline \multirow{2}{*}{ Bilirrubina Total } & $1,37(0,8)$ & $0,93(0,5)$ \\
\hline & $0,4-3,1$ & $0,3-2,1$ \\
\hline \multirow{2}{*}{ Bilirrubina Direta } & $0,4(0,2)$ & $0,3(0,3)$ \\
\hline & $0,1-1,2$ & $0,1-1,4$ \\
\hline \multirow{2}{*}{ Proteínas Totais } & $7,9(0,8)$ & $8,0(0,7)$ \\
\hline & $6,0-9,4$ & $7,0-9,2$ \\
\hline \multirow{2}{*}{ Albumina } & $4,2(0,6)$ & $4,3(0,4)$ \\
\hline & $3,0-5,2$ & $3,3-4,7$ \\
\hline \multirow{2}{*}{ Hemoglobina } & $14,6(1,4)$ & $13,6(1,6)$ \\
\hline & $11,0-17,1$ & $10,7-16,0$ \\
\hline \multirow{2}{*}{ Plaquetas } & $201015,9(62081,2)$ & $203071,4(55970,2)$ \\
\hline & $66000-341000$ & 103000 - 309000 \\
\hline \multirow{2}{*}{ Tempo de Protrombina } & $12,7(1,7)$ & $13,3(1,4)$ \\
\hline & $9,5-16,9$ & $10,8-15,7$ \\
\hline
\end{tabular}

NOTA: A média de CD4 em ambas as séries foi acima de 350, com média de 362,2 no grupo CIP e 378,1 no grupo SIP. Existe aparentemente uma contradição entre a média de CD4 e a carga viral HIV: média no grupo CIP de 53220,3 e média no grupo SIP de 17946,7. 


\section{$\underline{\text { V. Avaliação Histológica }}$}

\section{TABELA 10 - AVALIAÇÃO DO GRAU DE FIBROSE ${ }^{(*)}$ NA BIOPSIA HEPÁTICA NOS PACIENTES CO-INFECTADOS COM HIV- VHC DE ACORDO COM O TIPO DE TERAPIA ANTIRRETROVIRAL RECEBIDA}

\begin{tabular}{l|cc|cc}
\hline \multirow{2}{*}{ FIBROSE } & \multicolumn{5}{|c}{ GRUPO } \\
\cline { 2 - 6 } & \multicolumn{3}{|c|}{ CIP } & \multicolumn{3}{c}{ SIP } \\
& $\mathrm{n}$ & $(\%)$ & $\mathrm{n}$ & $(\%)$ \\
\hline $0-2$ & 49 & $(63,6)$ & 28 & $(80,0)$ \\
$3-4$ & 28 & $(36,4)$ & 7 & $(20,0)$ \\
TOTAL & 77 & $(100,0)$ & 35 & $(100,0)$
\end{tabular}

NOTA: O grau de fibrose observado nas biopsias hepáticas avaliadas de acordo com o Consenso da Sociedade Brasileira de Patologia foi predominantemente menor ou igual a dois em ambos os grupos, com percentagens de 63,6\% dos pacientes do grupo CIP e $80 \%$ dos pacientes do grupo SIP.

${ }^{(*)}$ Medido segundo o Consenso da Sociedade Brasileira de Patologia.

\section{TABELA 11 - AVALIAÇÃO DO GRAU DE ATIVIDADE NECRO- INFLAMATÓRIA ${ }^{(*)}$ NOS PACIENTES CO-INFECTADOS COM HIV-VHC DE ACORDO COM O TIPO DE TERAPIA ANTIRRETROVIRAL RECEBIDA}

\begin{tabular}{l|cc|cc}
\hline \multirow{2}{*}{ INFLAMAÇÃO } & \multicolumn{5}{|c}{ GRUPO } \\
\cline { 2 - 6 } & \multicolumn{3}{|c}{ CIP } & \multicolumn{3}{c}{ SIP } \\
& $\mathrm{n}$ & $(\%)$ & $\mathrm{n}$ & $(\%)$ \\
\hline $1-4$ & 26 & $(33,3)$ & 14 & $(40,0)$ \\
$5-7$ & 40 & $(51,3)$ & 15 & $(42,9)$ \\
$8-10$ & 12 & $(15,4)$ & 6 & $(17,1)$ \\
TOTAL & 78 & $(100,0)$ & 35 & $(100,0)$
\end{tabular}

NOTA: O grau de atividade necro-inflamatória observado nas biopsias hepáticas avaliadas de acordo com o Consenso da Sociedade Brasileira de Patologia foi majoritariamente entre 5 e 7 em ambos os grupos, com percentagens de $51,3 \%$ dos pacientes do grupo CIP e 42,9\% dos pacientes do grupo SIP.

(*) Medido como a somatória das alterações estrutural + portal + periportal + parenquimatosa observadas de acordo com Consenso da Sociedade Brasileira de Patologia. 


\section{6 - DISCUSSÃO}

Esse projeto de pesquisa foi desenvolvido com a participação de pacientes do Núcleo de Extensão para Atendimento de Pacientes com HIV/AIDS (Casa da AIDS) da Divisão de Clínica de Moléstias Infecciosas e Parasitárias do Hospital das Clínicas da Faculdade de Medicina da Universidade de São Paulo.

O desfecho do presente estudo foi obter uma análise inicial de dois grupos de pacientes, os que tomam esquema que incluam inibidores da protease ou não dentro do seu esquema HAART.

As possibilidades de viés são as mesmas de todo estudo baseado na revisão de prontuário: dados faltantes, não uniformidade na qualificação de parâmetros como raça, ocupação, consumo de álcool, fatores de risco e presença de doenças definidoras de AIDS ou uso de drogas hepatotrópicas, foram capturados nos prontuários dos pacientes durante uma consulta clínica comum e não usando um formulário padrão. Os tratamentos foram definidos de acordo com a resposta clínica do paciente e não mediante um diagrama de fluxo específico, sendo este também uma possibilidade de viés na análise dos casos.

\section{Características Demográficas}


Os dados demográficos nos estudos de co-infecção mostram populações predominantemente jovens.

O estudo de progressão de fibrose e cirrose em pacientes co-infectados do Hospital Universitário Puerta Del Mar (Cadiz, Espanha), apresenta uma população com média de 37,7 anos (34-39 anos com IC 95\%) no momento da biopsia hepática (94). O estudo do Instituto Científico San Rafael de Milão, Itália que compara o impacto do HAART na histologia HIV-VHC, o grupo de pacientes que haviam recebido HAART apresentaram média de idade de 37 anos. (97)

O estudo do Hospital Pietié-Salpêtrière de Paris, França, que observou fatores que afetavam a fibrose hepática em pacientes co-infectados HIV-VHC visando observar o impacto da terapia com inibidores da protease mostrou média de idade de 37,7 anos $( \pm 0,90)$ nos pacientes tratados com inibidores da protease e $36,30( \pm 0,50)$ anos nos que não os usaram. (77)

Em nossa análise, ambos os grupos tiveram média de idade de 41 anos no momento da realização da primeira biopsia, com uma diferença no desvio padrão em favor do grupo SIP (8,3 versus 7,6 anos).

A maioria dos pacientes não tinha educação profissional (técnica ou universitária). Para 7,1\% dos pacientes CIP e nenhum dos pacientes do grupo SIP foi relatado ter educação superior. A maior parte dos inquéritos populacionais realizados até o momento coincide na afirmação de que a prevalência de vírus de hepatite $\mathrm{C}$ se encontra inversamente relacionada ao grau de escolaridade. No estudo feito por Focaccia e colaboradores a proporção estimada de prevalência de hepatite $\mathrm{C}$ na cidade de São Paulo foi de 1,42\% (0,70\% - 2,12\% IC), no entanto os níveis educacionais universitários mostraram uma tendência muito baixa ou zero. (88) 


\section{Fatores de risco}

Foi identificado pelo menos um fator de risco para a infecção pelo HIV ou VHC em $93,2 \%$ dos pacientes CIP e $89,2 \%$ dos pacientes SIP.

Identificação de fatores de risco para contrair ambas as infecções tanto pelo HIV quanto pelo VHC são importantes em todos os estudos de co-infecção.

Ambos os vírus podem ser transmitidos através de exposição percutânea, através do intercurso sexual e de mãe para filho. Porém, a eficiência relativa de transmissão por essas vias pode variar. O VHC é aproximadamente 10 vezes mais infeccioso que o HIV através de exposições percutâneas, ele é transmitido em 15 a 30 de cada 1.000 exposições acidentais à perfuração por agulhas comparada com 3 por 1.000 para o HIV (antes do uso de profilaxia pós-exposição). Assim também, a incidência da infecção VHC e substancialmente maior que o HIV entre os usuários de drogas intravenosas. (93) 


\section{GRÁFICO 1 - PREVALÊNCIA DE ANTI-VHC EM PACIENTES HIV EM ACOMPANHAMENTO NA CLÍNICA DO HOSPITAL JOHN HOPKINS (N=1,955) DE ACORDO COM A CATEGORIA DE RISCO AUTO-REPORTADA}

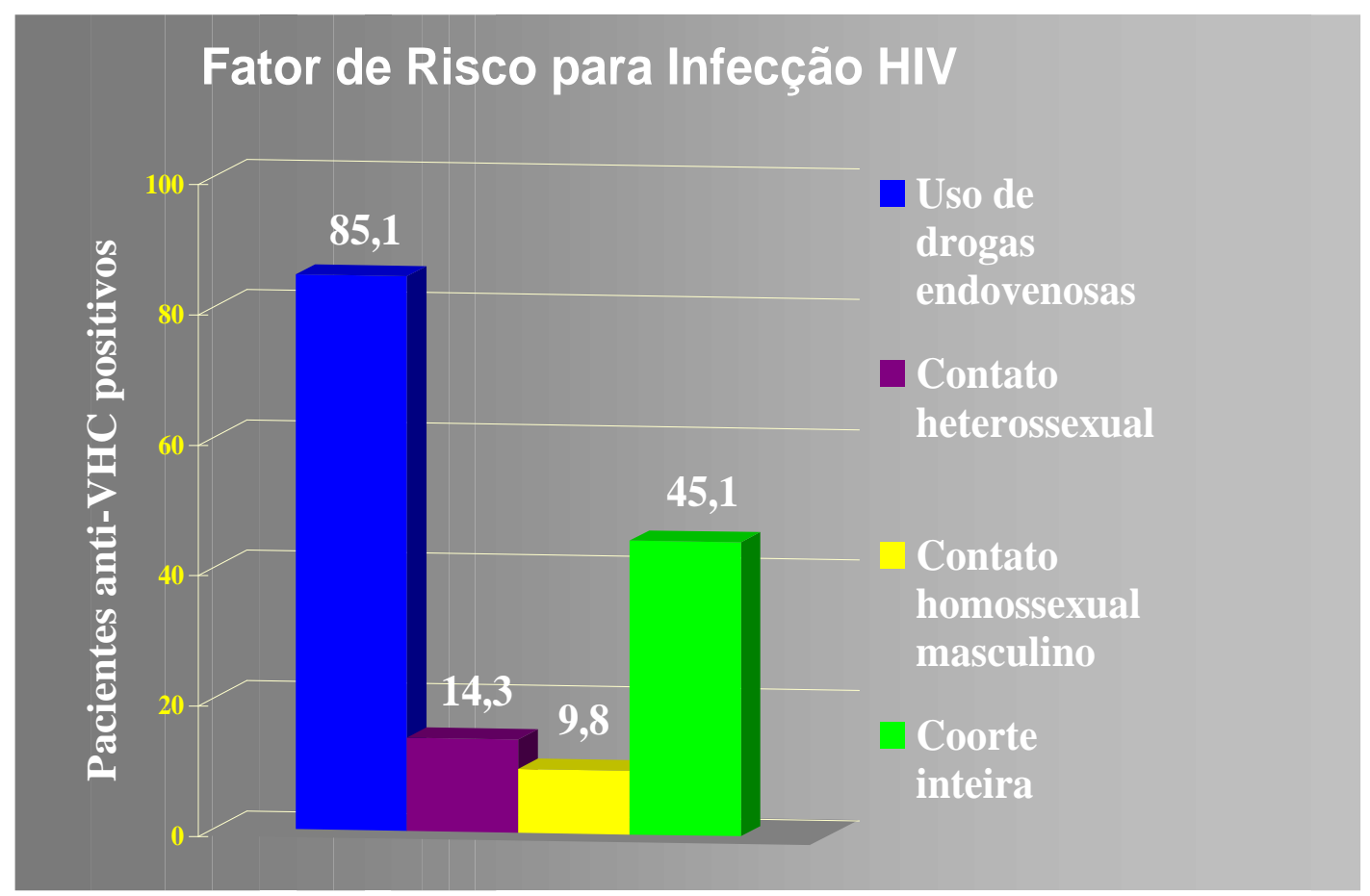

FONTE: Sulkowski MS, Thomas DL. Hepatitis C in the HIV-Infected Person. Ann Intern Med 2003 Feb 4;138(3):198.

Atualmente considera-se que a transfusão sangüínea como mecanismo de transmissão de ambos os vírus (VHC e HIV) tenha quase desaparecido. No período anterior ao desenvolvimento das provas sorológicas de identificação do VHC, de 5 a $12 \%$ dos pacientes nos Estados Unidos podem ter contraído hepatite aguda não-A, não-B por receber uma transfusão e $91 \%$ dessas infecções podem ter sido causadas pelo VHC (36). Desde que os testes sorológicos foram descobertos na década dos 80 , o risco residual de transmitir ambas as infecções praticamente não existe. (36)

A incidência decrescente de hepatites virais identificadas nos Estados Unidos nos anos 90 foi devido a inúmeros fatores: realização generalizada de exames sorológicos entre os doadores de sangue, programas de intercâmbio de seringas e 
programas educacionais nos maiores centros urbanos americanos (inicialmente uma resposta imediata a epidemia HIV) visando reduzir a propagação entre usuários de drogas intravenosas. $(11,74)$

\section{Consumo de álcool}

O consumo de álcool é tido como um importante fator de hepatotoxicidade que pode levar a diversos tipos de lesões no paciente com co-infecção HIV-VHC.

Um estudo do Instituto de Saúde Carlos III (Madrid, Espanha) que visa avaliar os fatores de risco para injúria hepática severa após a introdução de HAART mostra que o abuso de álcool foi o maior preditor de toxicidade hepática severa nos pacientes estudados. Foi realizado um estudo retrospectivo de revisão de prontuários entre janeiro de 1997 e janeiro de 2000, sendo 222 pacientes envolvidos com 38\% de prevalência de co-infecção HIV-VHC. Foi observado dano hepático severo em 9\% dos pacientes encontrando-se tanto no modelo de análise uni quanto multivariada a presença de abuso de álcool (RR 5,87; 95\% IC $\mathrm{p}=0,01$ ), sorologia positiva a VHC (RR 3,99; 95\% IC $\mathrm{p}=0,01$ ) e idade avançada (RR 1,11; 95\% IC $\mathrm{p}=0,001$ ). Neste estudo a injúria hepática foi definida pela elevação das enzimas hepáticas 1,25-2,5 xULN (Grau 1); 2,6-5xULN (Grau 2); 5,1-10xULN (Grau 3) e >10xULN (Grau 4) de toxicidade. (76)

Da mesma forma, no grupo de estudo do Hospital Pietié-Salpêtrière de Paris, França, durante um estudo que avaliou a progressão de fibrose hepática nos pacientes com e sem co-infecção HIV-VHC, mostrou que entre os pacientes co-infectados a idade no momento de infecção (>25 anos) e consumo de álcool (>50 g/d) foram 
fatores de risco independentes para desenvolver maiores taxas de progressão da fibrose hepática. Neste estudo também foi observado que o gênero não influenciou a taxa de progressão da fibrose nos pacientes co-infectados. (68)

\section{Presença de sintomas clínicos relacionáveis a doença hepática}

Desde a descoberta do VHC foi observado que a hepatite C trata-se de uma infecção que avança silenciosamente, oligo ou assintomático, até chegar a fibrosar totalmente o fígado ou produzir carcinoma hepatocelular.

Na literatura têm sido descritos casos de envolvimento de outros órgãos e sistemas extrahepáticos, envolvidos na doença causada pelo VHC. A infecção crônica pelo VHC tem sido relacionada com o desenvolvimento de doença glomerular renal. Uma equipe do Hospital de Harlem, Nova Iorque, junto a médicos do Centro Médico Presbiteriano da Universidade de Columbia, Estados Unidos, descrevem os achados clínico-patológicos de 14 pacientes que desenvolveram doença glomerular decorrente da co-infecção HIV-VHC. A apresentação foi de insuficiência renal, hematuria microscópica com sedimento urinário ativo, hipertensão e síndrome nefrótica ou proteinúria de nível nefrótico sem dislipidemia. Hipocomplementemia e crioglobulinemia estiveram presentes em 46 e $33 \%$ dos pacientes nos respectivos serviços. (14)

O Departamento de Medicina Interna do Hospital Pietié-Salpêtrière de Paris, França, publicou uma interessante revisão das principais manifestações extrahepáticas da infecção com o VHC, avaliando 321 pacientes VHC positivos que 
foram acompanhados em um estudo nacional com a participação de 15 departamentos de medicina interna de centros hospitalares de toda França.

Foram descritas doenças dermatológicas como púrpura, fenômeno de raynaud, vasculitis cutânea, pruritus, psoríase, porfiria cutânea tarda, lichen planus; envolvimento reumatológico com artralgias, artritis e mialgias; envolvimento neurológico com neuropatis sensória, e neuropatia motora e outros miscelaneos como síndrome sicca de boca e olho, hipertensão e uveite. (4)

Enquanto as manifestações hepáticas propriamente ditas, existem duas fases da doença hepática a serem determinadas: primeiramente, a fase aguda na qual tipicamente se observa elevação das transaminases a partir da segunda semana após a infecção, icterícia pode aparecer em menos de $20 \%$ dos casos freqüentemente acompanhada de fadiga, letargia, mialgias, febrícula, náusea, vômito e desconforto abdominal. Esta síndrome clínica, quando presente, se espera que ocorra entre as semanas 2 a 12 após a exposição. (11)

Na seqüência, a fase crônica, que acontece em $85 \%$ dos casos de infecção pelo VHC, aparentemente não diferiria daquela observada em pacientes HIV negativos.

\section{Parâmetros laboratoriais de acordo com o tipo de terapia antirretroviral recebido}

Hepatotoxicidade tem sido associada com todos os Inibidores da Protease atualmente aprovados pela FDA. Na HAART a hepatotoxicidade induzida por drogas tem sido mostrada como uma importante complicação na terapia de combinação, mais comumente com a administração do regime de dose total de Ritonavir em 
combinação com Saquinavir. Isso, adicionado ao fato da co-infecção com VHC, constitui um importante fator de risco no desenvolvimento de dano hepático induzido por drogas durante o uso de HAART. Mesmo que os estudos mostrem que os pacientes co-infectados com VHC podem ser tratados com segurança com Inibidores de Protease, deverão ser monitorados para identificar precocemente o aparecimento desta complicação. (82)

A presença de co-infecção com o VHC é um fator de risco independente para hepatotoxicidade relacionada com uso de antirretrovirais, mas a literatura não é rica em informações a respeito de qual o benefício de se tratar a infecção crônica pelo VHC no paciente co-infectado previamente ao início de uso de HAART. Um estudo prospectivo incluindo 105 pacientes foi realizado para comparar qual a incidência de progressão de toxicidade hepática severa relacionada ao uso de HAART em 66 pacientes tratados (36 com Interferon alfa, 30 com Interferon alfa e Ribavirina) e 39 pacientes não pré-tratados, sendo definida a toxicidade hepática severa como a elevação dos níveis de TGO em 5 ou mais vezes o nível normal em pacientes com TGO normal no início ou a elevação em 3,5 vezes ou mais em pacientes com elevação inicial da TGO.

Os autores deste estudo sugerem que o pré-tratamento poderia ser um fator independente associado com uma diminuição da hepatotoxicidade associada ao início de HAART. (83)

O estudo do efeito da HAART na carga viral VHC nos primeiros 3 anos de acompanhamento numa coorte espanhola de 21 pacientes co-infectados HIV-VHC, mostrou que a maioria dos pacientes co-infectados em uso de HAART nos 3 primeiros anos mantém uma viremia estável para o VHC sem modificações 
significativas das cifras de enzimas hepáticas, sendo em 2 dos casos observada a negativação permanente dos valores de carga viral VHC. (100)

6. Impacto da HAART na histologia hepática de pacientes co-infectados HIV$\mathrm{VHC}$

O impacto da HAART na progressão da doença hepática relacionada ao VHC é controverso.

Alguns autores sugerem que o uso de Inibidores da Protease no esquema HAART por 10 a 16 meses poderia estar associado a uma melhor evolução da fibrose em relação àqueles com esquemas HAART sem Inibidores da Protease. Foi realizado um estudo comparando a graduação e evolução da hepatite viral crônica produzida em pacientes co-infectados HIV e VHC tratados ou não com esquema HAART que inclua Inibidores da Protease. A histologia hepática de 44 pacientes em HAART por mais de 12 meses, 26 pacientes virgens de tratamento para HAART e 31 pacientes monoinfectados VHC foram analisados pelo escore Ishak. Nenhum dos modelos multivariados usados para avaliar a histopatologia hepática entre os pacientes co-infectados HIV-VHC e os pacientes monoinfectados VHC ou os tratados com HAART com ou sem Inibidores da Protease em comparação com os não tratados HIV+ mostrou alguma diferença estatística de evolução. (97)

Mas a maioria dos estudos coincide em que a presença de hepatotoxicidade relacionada a drogas seria mais freqüente em pacientes que usam HAART que incluam Inibidores da Protease, sem concluir se existe relação com a evolução histológica da doença produzida pelo VHC, não sendo na maior parte das ocasiões necessário descontinuar a terapia pelo efeito colateral de hepatotoxicidade. (99) 


\section{7 - CONCLUSÕES}

1. Ambas as populações estudadas apresentaram características demográficas similares;

2. Foi possível determinar em ambas as populações estudadas a fonte potencial de risco para aquisição de ambas infecções em mais de $85 \%$ dos casos;

3. As biopsias hepáticas dos pacientes mostraram baixo grau de fibrose $(63,6 \%$ no grupo CIP e $80 \%$ no grupo SIP) e um grau médio de atividade necroinflamatória (51,3\% no grupo CIP e 42,9\% no grupo SIP);

4. Para acompanhar a evolução da doença hepática em ambos os grupos, novas biopsias deverão ser feitas, com o desfecho de determinar qual a diferença da evolução da doença hepática em ambos os grupos de acordo com o tipo de terapia HAART recebida. 
ANEXO 1

\section{Anexo 1}

TABELA DE OBTENÇÃO DE DADOS

\section{DADOS GERAIS}

\section{Filiação}

1. Paciente:

2. Prontuário:

3. Sexo:

4. Cor:

5. Ocupação:

6. Data de identificação como portador HIV (Western blot positivo):

7. Data de identificação como portador VHC (PCR positivo):

\section{$\underline{\text { Antecedentes }}$}

a) Fonte potencial de infecção pelos vírus HIV-VHC

- Sangue, derivados de sangue, órgãos, tecidos de doadores infectados

- Drogadição intravenosa

- Uso de artigos potencialmente infectados (medicina tradicional ou folclórica, tatuagens, "body piercing")

- Contato infectado

- Conduta sexual de risco

- Transmissão materno-fetal

\section{b) Uso de álcool}

- Nenhum

- Social

- Habitual

c) Doenças Concomitantes: (escrever)

d) Uso de drogas hepatotóxicas além do tratamento: (escrever) 


\section{DADOS CLÍNICOS}

\section{a) Sintomas apresentados durante a doença}

- Icterícia

- Hematêmese

- Aranhas vasculares

- Ascite

- Melena

- Ginecomastia

- Edemas

- Circulação Colateral

- Eritema Palmar

- Outros

TABELA DE SEGUIMENTO DE TERAPIA ANTIRRETROVIRAL: colocar em ordem os esquemas terapêuticos utilizados.

\begin{tabular}{|l|l|l|}
\hline \multicolumn{1}{|c|}{ Data } & Ano 0 & Ano 2 \\
\hline 2NRTI+IP & & \\
\hline 2NRTI+NNRTI & & \\
\hline 2NRTI+ABC & & \\
\hline Outros & & \\
\hline
\end{tabular}

TABELA DE SEGUIMENTO LABORATORIAL

\begin{tabular}{|l|l|l|}
\hline \multicolumn{1}{|c|}{ Data } & Ano 0 & Ano 2 \\
\hline Carga Viral HIV & & \\
\hline CD4 & & \\
\hline PCR-VHC (Qualitativo) & & \\
\hline TGO & & \\
\hline TGP & & \\
\hline GGT & & \\
\hline Fosfatase Alcalina & & \\
\hline Bilirrubina Total & & \\
\hline Bilirrubina Direta & & \\
\hline Proteínas Totais & & \\
\hline Albumina & & \\
\hline Hemoglobina & & \\
\hline Plaquetas & & \\
\hline TP & & \\
\hline
\end{tabular}


ESCORE DE EVOLUÇÃO DA DOENCA HEPÁTICA

\begin{tabular}{|l|c|}
\hline \multicolumn{1}{|c|}{ Alteração } & Escore \\
\hline Enzimas hepáticas & 0 \\
Normais & 1 \\
Até 3X & 2 \\
Acima de 3X & \\
\hline PCR-VHC & 0 \\
Negativo & 1 \\
Positivo & \\
\hline Grau de atividade histopatológica & 0 \\
Fibrose & 1 \\
0 pontos & 2 \\
1-2 pontos & \\
3-4 pontos & 0 \\
Atividade necro-inflamatória & 1 \\
0-3 pontos & 2 \\
4-8 pontos & \\
9-12 pontos & \\
\hline
\end{tabular}

Atividade:

Baixa: $\quad 0-2$ pontos

Média: 3-4 pontos

Alta: $\quad 5-7$ pontos 


\section{Anexo 2}

ANEXO 2

Critério Rio de Janeiro/Caracas de definição de caso de AIDS (Ministério da Saúde)

Será considerado Caso de AIDS, para fins de vigilância epidemiológica, todo indivíduo com 13 anos de idade ou mais que apresentar evidência laboratorial de infecção pelo HIV e pelo menos um somatório de 10 pontos, de acordo com a seguinte escala de sinais, sintomas ou doenças:

\section{SINAIS / SINTOMAS / DOENÇAS}

PONTOS

sarcoma de Kaposi

tuberculose disseminada/extrapulmonar/pulmonar não cavitária

candidíase oral ou leucoplasia pilosa

tuberculose pulmonar cavitária ou não especificada

herpes zoster em indivíduo com até 60 anos de idade

disfunção do sistema nervoso central

diarréia por um período igual ou superior a 1 mês

febre igual ou superior a $38^{\circ} \mathrm{C}$, por um período igual ou superior a 1 mês

caquexia ou perda de peso corporal superior a $10 \%$

astenia por um período igual ou superior a 1 mês

dermatite persistente

anemia e/ou linfopenia e/ou trombocitopenia

tosse persistente ou qualquer pneumonia (exceto tuberculose)

linfadenopatia maior ou igual a $1 \mathrm{~cm}$, maior ou igual a 2 sítios extraingüinais, por um período igual ou superior a 1 mês 
ANEXO 3

Anexo 3

\section{Drogas Hepatotóxicas}

\begin{tabular}{|lll|}
\hline \multicolumn{2}{|c|}{ DROGAS QUE PRODUZEM COLESTASE } \\
Aminosalicílico, ácido & Dapsona & Nitrofurantoína \\
Amitriptilina & Eritromicina & Sais de Ouro \\
Anabólicos, esteroides & Estrógenos & Penicilamina \\
Andrógenos & Etionamida & Penicilinas \\
Anticonceptivos orais & Fenilbutazona & Progestinas \\
Azatioprina & Fenotiazinas & Propoxifeno \\
Benzodiazepinas & Gliburida (glibenclamida) & Sulfonamidas \\
Carbamacepinas & Imipramina & Sulfonas \\
Carbarsona & Mercaptopurina & Sulindaco \\
Clavulânico, ácido & Metimazol & Tamoxifeno \\
Clorotiazida & Mitoxantrona & Tolbutamida \\
Clorpropamida & Nicotínico, ácido & \\
\hline
\end{tabular}




\begin{tabular}{|c|c|c|}
\hline \multicolumn{3}{|c|}{ DROGAS QUE PRODUZEM INJÚRIA HEPATOCELULAR } \\
\hline Acetaminofeno & Disulfiram & Naproxeno \\
\hline Alopurinol & Estrógenos & Nicotínico, ácido \\
\hline Aminosalicílico, ácido & Etanol (excesso) & Nitrofurantoína \\
\hline Amiodarona & Etionamida & Papaverina \\
\hline Amitriptilina & Etretinato & Parametadioma \\
\hline Anabólicos, esteroides & Fenazopiridina & Perhexilina \\
\hline Andrógenos & Fenindiona & Pirazinamida \\
\hline Anticonceptivos orais & Fenobarbital & Plicamicina (mitramicina) \\
\hline Asparaginase & Fenilbutazona & Probenecida \\
\hline Aspirina & Fenotoína & Procainamida \\
\hline Azatioprina & Fluconazole & Propiltiouracilo \\
\hline Carbamazepina & Halotano & Quinidina \\
\hline Chenodiol & Sais de Ferro (overdose) & Rifampina \\
\hline Clorambucil & Ibuprofeno & Salicilatos \\
\hline Cloranfenicol (ocasional) & Imipramina & Sulfasalazina \\
\hline Clorpropamida & Indometacina & Sulfonamidas \\
\hline Ciclosporina & Isoniazida & Tamoxifeno \\
\hline Cimetidina & Cetoconazol & Tetraciclinas \\
\hline Danazol & $M A O$, inibidores & Trimetadiona \\
\hline Dantroleno & Mercaptopurina & Valproíco, ácido \\
\hline Dapsona & Metotrexato & Vitamina A \\
\hline Diclofenaco & Metoxiflurano & Warfarina (raro) \\
\hline Dicoumarol (raro) & Metildopa & \\
\hline
\end{tabular}


Anexo 4

ANEXO 4

Critérios de semiquantificação das biopsias hepáticas de acordo com o Consenso Nacional sobre a Classificação das Hepatites Crônicas (Projeto do Clube de Patologia Hepática da Sociedade Brasileira de Patologia, aprovado pela Sociedade Brasileira de Hepatologia (GED 19(3)137-140: Mai/Jun 2000)

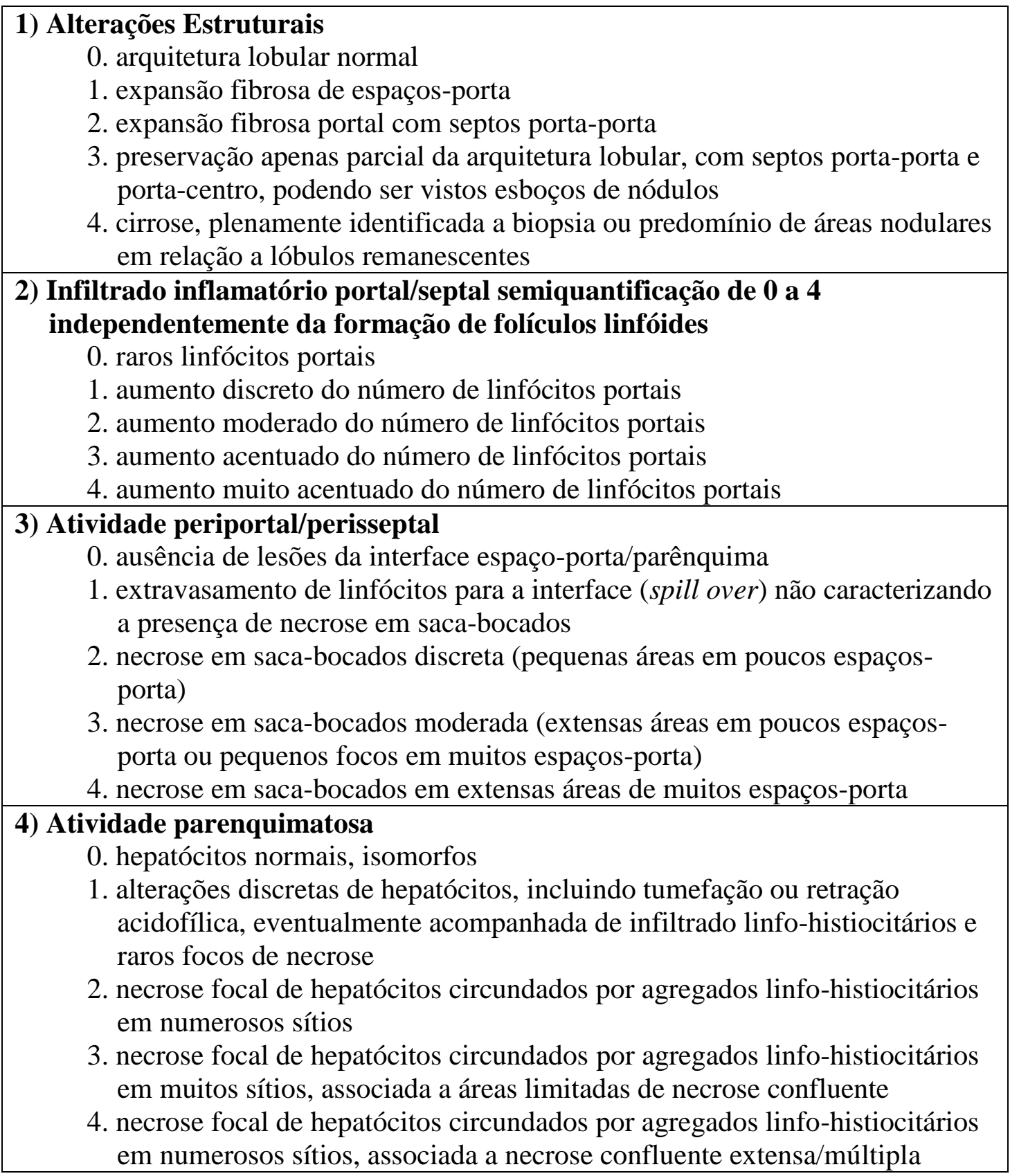




\section{9 - REFERÊNCIAS BIBLIOGRÁFICAS}

1. Global Prevalence of Hepatitis A, B, and C. Wkly Epidemiol Rec 2002; 77:6.

2. Saillour F, Dabis F, Dupon M, Lacoste D, et al. Prevalence and determinants of antibodies to hepatitis $\mathrm{C}$ virus and markers for hepatitis B virus infection in patients with HIV infection in Aquitaine. Groupe d'Epidemiologie Clinique du SIDA en Aquitaine. BMJ 1996;Aug 24;313(7055):461-4.

3. Poles MA, Lew EA, Dieterich DT. Diagnosis and treatment of hepatic disease in patients with HIV. Gastroenterol Clin North Am 1997 Jun;26(2):291-321. Review.

4. Cacoub P, Renou C, Rosenthal E, Cohen P, Loury I, Loustaud-Ratti V, Yamamoto AM, Camproux AC, Hausfater P, Musset L, Veyssier P, Raguin G, Piette JC. Extrahepatic manifestations associated with hepatitis $\mathrm{C}$ virus infection. A prospective multicenter study of 321 patients. The GERMIVIC. Groupe d'Etude et de Recherche en Medecine Interne et 
Maladies Infectieuses sur le Virus de l'Hepatite C. Medicine (Baltimore) 2000 Jan;79(1):47-56.

5. Gonzáles-Peralta RP. Hepatitis C virus infection in pediatric patients. Clin Liver Dis 1997 Nov;1(3):691-704.

6. Schiff ER, Martin Tagle F. Hepatitis C treatment of HCV: approach to difficult cases. Clin Liver Dis 1997 Nov;1(3):647-60.

7. Talal AH, Weiss LM, Vanderhorst C. Molecular diagnosis of gastrointestinal infections associated with HIV infection. Gastroenterol Clin North Am 1997 Jun;26(2):417-44. Review.

8. Gerber MA. Hepatitis C histopatology of HCV infection. Clin Liver Dis 1997 Nov;1(3):529-40.

9. Alter MJ. Hepatitis C: the epidemiology of acute and chronic hepatitis C. Clin Liver Dis 1997 Nov;1(3):559-68.

10. Granovsky MO, Minkoff HL, Tess BH, Waters D, Hatzakis A, Devoid DE, Landesman SH, Rubinstein A, Di Bisceglie AM, Goedert JJ. Hepatitis C virus infection in the mothers and infants cohort study. Pediatrics 1998 Aug;102(2 Pt 1):355-9. 
11. Orland JR, Wright TL, Cooper S. Acute hepatitis C. Hepatology 2001 Feb;33(2):321-7. Review.

12. Garcia-Samaniego J, Soriano V, Castilla J, Bravo R, Moreno A, Carbo J, Iniguez A, Gonzalez J, Munoz F. Influence of hepatitis $\mathrm{C}$ virus genotypes and HIV infection on histological severity of chronic hepatitis C. The Hepatitis/HIV Spanish Study Group. Am J Gastroenterol 1997 Jul;92(7):1130-4.

13. Da Costa Gayotto LC, Comitê SBP/SBI. Visão histórica e Consenso Nacional sobre a classificação das hepatites crônicas. Projeto do Clube de Patologia Hepática da Sociedade Brasileira de Patologia aprovada pela Sociedade Brasileira de Hepatologia. GED Mai/Jun 2000;19(3):137-40.

14. Cheng JT, Anderson HL Jr, Markowitz GS, Appel GB, Pogue VA, D'Agati VD. Hepatitis C virus-associated glomerular disease in patients with human immunodeficiency virus coinfection. J Am Soc Nephrol 1999 Jul;10(7):1566-74.

15. Monsuez JJ, Vittecoq D, Musset L, Alemanni M, Dussaix E, Autran B. Arthralgias and cryoglobulinemia during protease inhibitor therapy in a patient infected with human immunodeficiency virus and hepatitis $\mathrm{C}$ virus. Arthritis Rheum 1998 Apr;41(4):740-3. 
16. Patterson JM, Novak CB, Mackinnon SE, Patterson GA. Surgeons' concern and practices of protection against bloodborne pathogens. Ann Surg 1998 Aug;228(2):266-72.

17. Lemon SM, Brown EA. Hepatitis C. In: Mandell GL, Bennett JE, Dolin R, editors. Principles and Practice of Infectious Diseases, 4th ed. Vol. 2, Part III 1995. p. 1474-85.

18. Mendes-Corrêa MC, Barone AA, Guastini C. Hepatitis C virus seroprevalence and risk factors among patients with HIV infection. Rev Inst Med Trop S Paulo Feb 2001;43(1):15-19.

19. Ross RS, Viazov S, Gross T, Hofmann F, Seipp HM, Roggendorf M. Transmission of hepatitis $\mathrm{C}$ virus from a patient to an anesthesiology assistant to five patients. N Engl J Med 2000 Dec 21;343(25):1851-4.

20. Davis GL, Esteban-Mur R, Rustgi V, Hoefs J, Gordon SC, Trepo C, Shiffman ML, Zeuzem S, Craxi A, Ling MH, Albrecht J. Interferon alfa-2b alone or in combination with ribavirin for the treatment of relapse of chronic hepatitis C. International Hepatitis Interventional Therapy Group. N Engl J Med 1998 Nov 19;339(21):1493-9. 
21. van Beek I, Dwyer R, Dore GJ, Luo K, Kaldor JM. Infection with HIV and hepatitis $\mathrm{C}$ virus among injecting drug users in a prevention setting: retrospective cohort study. BMJ 1998 Aug 15;317(7156):433-7.

22. Spector SA. Mother-to-infant transmission of HIV-1: the placenta fights back. J Clin Invest 2001 Feb;107(3):267-9.

23. Patterson BK, Behbahani H, Kabat WJ, Sullivan Y, O'Gorman MR, Landay A, Flener Z, Khan N, Yogev R, Andersson J. Leukemia inhibitory factor inhibits HIV-1 replication and is upregulated in placentae from nontransmitting women. J Clin Invest 2001 Feb;107(3):287-94.

24. Neary MP, Cort S, Bayliss MS, Ware JE Jr. Sustained virologic response is associated with improved health-related quality of life in relapsed chronic hepatitis C patients. Semin Liver Dis 1999;19 Suppl 1:77-85.

25. Davis GL. Combination therapy with interferon alfa and ribavirin as retreatment of interferon relapse in chronic hepatitis C. Semin Liver Dis 1999;19 Suppl 1:49-55. Review.

26. Jonas MM. Hepatitis C infection in children. N Engl J Med 1999 Sep 16;341(12):912-3. 
27. Bortolotti F, Resti M, Giacchino R, Azzari C, Gussetti N, Crivellaro C, Barbera C, Mannelli F, Zancan L, Bertolini A. Hepatitis C virus infection and related liver disease in children of mothers with antibodies to the virus. J Pediatr 1997 Jun;130(6):990-3.

28. Inoue T, Sakamoto M, Akahane Y, Okamoto H, Miyakawa Y, Mayumi M. Response to interferon of GB virus $\mathrm{C}$ and hepatitis $\mathrm{C}$ virus in patients with chronic hepatitis. Am J Gastroenterol 1997 Nov;92(11):1981-5.

29. Giacchino R, Tasso L, Timitilli A, Castagnola E, Cristina E, Sinelli N, Gotta C, Giambartolomei G, Moscatelli P, Picciotto A. Vertical transmission of hepatitis C virus infection: usefulness of viremia detection in HIVseronegative hepatitis C virus-seropositive mothers. J Pediatr 1998 Jan;132(1):167-9.

30. Piroth L, Duong M, Quantin C, Abrahamowicz M, Michardiere R, Aho LS, Grappin M, Buisson M, Waldner A, Portier H, Chavanet P. Does hepatitis $\mathrm{C}$ virus co-infection accelerate clinical and immunological evolution of HIV-infected patients? AIDS 1998 Mar 5;12(4):381-8.

31. Yokozaki S, Takamatsu J, Nakano I, Katano Y, Toyoda H, Hayashi K, Hayakawa T, Fukuda Y. Immunologic dynamics in hemophiliac patients infected with hepatitis $\mathrm{C}$ virus and human immunodeficiency virus: influence of antiretroviral therapy. Blood 2000 Dec 15;96(13):4293-9. 
32. Davis GL, Nelson DR, Reyes GR. Future options for the management of hepatitis C. Semin Liver Dis 1999;19 Suppl 1:103-12. Review.

33. Rockstroh JK, Spengler U, Sudhop T, Ewig S, Theisen A, Hammerstein U, Bierhoff E, Fischer HP, Oldenburg J, Brackmann HH, Sauerbruch T. Immunosuppression may lead to progression of hepatitis C virusassociated liver disease in hemophiliacs coinfected with HIV. Am J Gastroenterol 1996 Dec;91(12):2563-8.

34. Barnes E, Webster G, Whalley S, Dusheiko G. Predictors of a favorable response to alpha interferon therapy for hepatitis C. Clin Liver Dis 1999 Nov;3(4):775-91. Review.

35. Sung CC, Boomer JS, Givens TS, DuChateau BK, Lepe MR, Feller A, Westerman MP, Gilman-Sachs A, Chedid A, Beaman KD. Expression of regeneration and tolerance factor correlates directly with human immunodeficiency virus infection and inversely with hepatitis $\mathrm{C}$ virus infection. Clin Diagn Lab Immunol 2000 Mar;7(2):200-5.

36. Tong MJ, el-Farra NS, Reikes AR, Co RL. Clinical outcomes after transfusion-associated hepatitis C. N Engl J Med 1995 Jun 1;332(22):14636. 
37. Piroth L, Grappin M, Sgro C, Buisson M, Duong M, Chavanet P. Recurrent NNRTI-induced hepatotoxicity in an HIV-HCV-coinfected patient. Ann Pharmacother 2000 Apr;34(4):534-5.

38. Malnick SD, Beergabel M, Lurie Y. Treatment of chronic hepatitis C virus infection. Ann Pharmacother 2000 Oct;34(10):1156-64. Review.

39. Graham CS, Koziel MJ. Why should hepatitis C affect immune reconstitution in HIV-1-infected patients? Lancet 2000 Dec 2;356(9245):1865-6.

40. Greub G, Ledergerber B, Battegay M, Grob P, Perrin L, Furrer H, Burgisser P, Erb P, Boggian K, Piffaretti JC, Hirschel B, Janin P, Francioli P, Flepp M, Telenti A. Clinical progression, survival, and immune recovery during antiretroviral therapy in patients with HIV-1 and hepatitis $\mathrm{C}$ virus coinfection: the Swiss HIV Cohort Study. Lancet 2000 Nov 25;356(9244):1800-5. Erratum in: Lancet. 2001 May 12;357(9267):1536.

41. Lafeuillade A, Hittinger G, Chadapaud S. Increased mitochondrial toxicity with ribavirin in $\mathrm{HIV} / \mathrm{HCV}$ coinfection. Lancet 2001 Jan 27;357(9252):280-1.

42. Poynard T, Marcellin P, Lee SS, Niederau C, Minuk GS, Ideo G, Bain V, Heathcote J, Zeuzem S, Trepo C, Albrecht J. Randomised trial of interferon alpha $2 \mathrm{~b}$ plus ribavirin for 48 weeks or for 24 weeks versus 
interferon alpha $2 \mathrm{~b}$ plus placebo for 48 weeks for treatment of chronic infection with hepatitis $\mathrm{C}$ virus. International Hepatitis Interventional Therapy Group (IHIT). Lancet 1998 Oct 31;352(9138):1426-32.

43. Toyoda H, Fukuda Y, Takamatsu J. Clearance of hepatitis G viremia in a human immunodeficiency virus-positive patient by high-activity antiretroviral therapy. Clin Infect Dis 1999 Nov;29(5):1332-3.

44. Soriano V, Rodriguez-Rosado R, Garcia-Samaniego J. Management of chronic hepatitis C in HIV-infected patients. AIDS 1999 Apr 1;13(5):53946. Review.

45. Zeuzem S, Feinman SV, Rasenack J, Heathcote EJ, Lai MY, Gane E, O'Grady J, Reichen J, Diago M, Lin A, Hoffman J, Brunda MJ. Peginterferon alfa-2a in patients with chronic hepatitis C. N Engl J Med 2000 Dec 7;343(23):1666-72.

46. Heathcote EJ, Shiffman ML, Cooksley WG, Dusheiko GM, Lee SS, Balart L, Reindollar R, Reddy RK, Wright TL, Lin A, Hoffman J, De Pamphilis J. Peginterferon alfa-2a in patients with chronic hepatitis $\mathrm{C}$ and cirrhosis. $\mathrm{N}$ Engl J Med 2000 Dec 7;343(23):1673-80.

47. Poles MA, Dieterich DT. Infections of the liver in HIV-infected patients. Infect Dis Clin North Am 2000 Sep;14(3):741-59. Review. 
48. Musselman DL, Lawson DH, Gumnick JF, Manatunga AK, Penna S, Goodkin RS, Greiner K, Nemeroff CB, Miller AH. Paroxetine for the prevention of depression induced by high-dose interferon alfa. $\mathrm{N}$ Engl $\mathbf{J}$ Med 2001 Mar 29;344(13):961-6.

49. Rodriguez-Inigo E, Bartolome J, de Lucas S, Manzarbeitia F, Pardo M, Arocena C, Gosalvez J, Oliva H, Carreno V. Histological damage in chronic hepatitis $\mathrm{C}$ is not related to the extent of infection in the liver. Am J Pathol 1999 Jun;154(6):1877-81.

50. Lim HW, Pereira A, Sassa S, Kim M, Zolla-Pazner S. Early-stage HIV infection and hepatitis $\mathrm{C}$ virus infection are associated with elevated serum porphyrin levels. J Am Acad Dermatol 1998 Dec;39(6):956-9.

51. NIH Consensus Statement. Management of Hepatitis C. 1997 March 24-26, 15(3).

52. Thio CL, Nolt KR, Astemborski J, Vlahov D, Nelson KE, Thomas DL. Screening for hepatitis $\mathrm{C}$ virus in human immunodeficiency virus-infected individuals. J Clin Microbiol 2000 Feb;38(2):575-7.

53. Karras A, Rabian C, Zylberberg H, Hermine O, Duchatelle V, Durand F, Valla D, Viard JP. Severe anoxic hepatic necrosis in an HIV-1-hepatitis C 
virus-co-infected patient starting antiretroviral triple combination therapy. AIDS 1998 May 7;12(7):827-9.

54. Rockstroh JK, Theisen A, Kaiser R, Sauerbruch T, Spengler U. Antiretroviral triple therapy decreases HIV viral load but does not alter hepatitis $\mathrm{C}$ virus (HCV) serum levels in HIV-HCV-co-infected haemophiliacs. AIDS 1998 May 7;12(7):829-30.

55. Gholson CF, Morgan K, Catinis G, Favrot D, Taylor B, Gonzalez E, Balart L. Chronic hepatitis $\mathrm{C}$ with normal aminotransferase levels: a clinical histologic study. Am J Gastroenterol 1997 Oct;92(10):1788-92.

56. Ferrari JO, Ferreira MU, Tanaka A, Mizokami M. The seroprevalence of hepatitis $\mathrm{B}$ and $\mathrm{C}$ in an Amerindian population in the southwestern Brazilian Amazon. Rev Soc Bras Med Trop 1999 May-Jun;32(3):299-302.

57. Diepolder HM, Gerlach JT, Zachoval R, Hoffmann RM, Jung MC, Wierenga EA, Scholz S, Santantonio T, Houghton M, Southwood S, Sette A, Pape GR. Immunodominant CD4+ T-cell epitope within nonstructural protein 3 in acute hepatitis C virus infection. J Virol 1997 Aug;71(8):6011-9.

58. Berger A, Preiser W, Doerr HW. The role of viral load determination for the management of human immunodeficiency virus, hepatitis B virus and hepatitis C virus infection. J Clin Virol 2001 Jan;20(1-2):23-30. Review. 
59. Thomas SL, Newell ML, Peckham CS, Ades AE, Hall AJ. A review of hepatitis $\mathrm{C}$ virus $(\mathrm{HCV})$ vertical transmission: risks of transmission to infants born to mothers with and without $\mathrm{HCV}$ viraemia or human immunodeficiency virus infection. Int J Epidemiol 1998 Feb;27(1):108-17. Review.

60. Brunt EM. Grading and staging the histopathological lesions of chronic hepatitis: the Knodell histology activity index and beyond. Hepatology 2000 Jan;31(1):241-6. Review.

61. Sulkowski MS, Mast EE, Seeff LB, Thomas DL. Hepatitis C virus infection as an opportunistic disease in persons infected with human immunodeficiency virus. Clin Infect Dis 2000 Apr;30 Suppl 1:S77-84. Review.

62. Dove LM, Alonzo J, Wright TL. Clinicopathological conference: hepatitis C in a patient with human immunodeficiency virus infection. Hepatology $2000 \mathrm{Jul} ; 32(1): 147-52$.

63. Sobao Y, Tomiyama H, Nakamura S, Sekihara H, Tanaka K, Takiguchi M. Visual demonstration of hepatitis C virus-specific memory CD8(+) T-cell expansion in patients with acute hepatitis C. Hepatology 2001 Jan;33(1):287-94. 
64. Murakami J, Shimizu Y, Kashii Y, Kato T, Minemura M, Okada K, Nambu S, Takahara T, Higuchi K, Maeda Y, Kumada T, Watanabe A. Functional B-cell response in intrahepatic lymphoid follicles in chronic hepatitis C. Hepatology 1999 Jul;30(1):143-50.

65. Collier J, Heathcote J. Hepatitis C viral infection in the immunosuppressed patient. Hepatology 1998 Jan;27(1):2-6. Review.

66. Wiedmann M, Liebert UG, Oesen U, Porst H, Wiese M, Schroeder S, Halm U, Mossner J, Berr F. Decreased immunogenicity of recombinant hepatitis B vaccine in chronic hepatitis C. Hepatology 2000 Jan;31(1):230-4.

67. Keeffe EB, Iwarson S, McMahon BJ, Lindsay KL, Koff RS, Manns M, Baumgarten R, Wiese M, Fourneau M, Safary A, Clemens R, Krause DS. Safety and immunogenicity of hepatitis A vaccine in patients with chronic liver disease. Hepatology 1998 Mar;27(3):881-6.

68. Benhamou Y, Bochet M, Di Martino V, Charlotte F, Azria F, Coutellier A, Vidaud M, Bricaire F, Opolon P, Katlama C, Poynard T. Liver fibrosis progression in human immunodeficiency virus and hepatitis $\mathrm{C}$ virus coinfected patients. The Multivirc Group. Hepatology 1999 Oct;30(4):1054-8. 
69. Pawlotsky JM. Hepatitis C virus resistance to antiviral therapy. Hepatology 2000 Nov;32(5):889-96. Review.

70. Sherman KE, Andreatta C, O'Brien J, Gutierrez A, Harris R. Hepatitis C in human immunodeficiency virus-coinfected patients: increased variability in the hypervariable envelope coding domain. Hepatology 1996 Apr;23(4):688-94.

71. Cerny A, Chisari FV. Pathogenesis of chronic hepatitis C: immunological features of hepatic injury and viral persistence. Hepatology 1999 Sep;30(3):595-601. Review.

72. Conte D, Fraquelli M, Prati D, Colucci A, Minola E. Prevalence and clinical course of chronic hepatitis $\mathrm{C}$ virus (HCV) infection and rate of $\mathrm{HCV}$ vertical transmission in a cohort of 15,250 pregnant women. Hepatology 2000 Mar;31(3):751-5.

73. Lauer GM, Walker BD. Hepatitis C virus infection. N Engl J Med 2001 Jul 5;345(1):41-52. Review.

74. Hahn JA, Page-Shafer K, Lum PJ, Ochoa K, Moss AR. Hepatitis C virus infection and needle exchange use among young injection drug users in San Francisco. Hepatology 2001 Jul;34(1):180-7. 
75. Saves M, Raffi F, Clevenbergh P, Marchou B, Waldner-Combernoux A, Morlat P, Le Moing V, Riviere C, Chene G, Leport C. Hepatitis B or hepatitis $\mathrm{C}$ virus infection is a risk factor for severe hepatic cytolysis after initiation of a protease inhibitor-containing antiretroviral regimen in human immunodeficiency virus-infected patients. The APROCO Study Group. Antimicrob Agents Chemother 2000 Dec;44(12):3451-5.

76. Nunez M, Lana R, Mendoza JL, Martin-Carbonero L, Soriano V. Risk factors for severe hepatic injury after introduction of highly active antiretroviral therapy. J Acquir Immune Defic Syndr 2001 Aug 15;27(5):426-31.

77. Benhamou Y, Di Martino V, Bochet M, Colombet G, Thibault V, Liou A, Katlama C, Poynard T; MultivirC Group. Factors affecting liver fibrosis in human immunodeficiency virus-and hepatitis $\mathrm{C}$ virus-coinfected patients: impact of protease inhibitor therapy. Hepatology 2001 Aug;34(2):283-7.

78. Allwright S, Bradley F, Long J, Barry J, Thornton L, Parry JV. Prevalence of antibodies to hepatitis B, hepatitis C, and HIV and risk factors in Irish prisoners: results of a national cross sectional survey. BMJ $2000 \mathrm{Jul}$ $8 ; 321(7253): 78-82$.

79. Mohsen AH, Easterbrook P, Taylor CB, Norris S. Hepatitis C and HIV-1 coinfection. Gut 2002 Oct;51(4):601-8. 
80. Zhang C, Yang R, Xia X, Qin S, Dai J, Zhang Z, Peng Z, Wei T, Liu H, Pu D, Luo J, Takebe Y, Ben K. High prevalence of HIV-1 and hepatitis C virus coinfection among injection drug users in the southeastern region of Yunnan, China. J Acquir Immune Defic Syndr 2002 Feb 1;29(2):191-6.

81. Mehta SH, Moore RD, Thomas DL, Chaisson RE, Sulkowski MS. The effect of HAART and HCV infection on the development of hyperglycemia among HIV-infected persons. J Acquir Immune Defic Syndr 2003 Aug $15 ; 33(5): 577-84$.

82. Sulkowski MS. Hepatotoxicity associated with antiretroviral therapy containing HIV-1 protease inhibitors. Semin Liver Dis 2003 May;23(2):183-94. Review.

83. Uberti-Foppa C, De Bona A, Morsica G, Galli L, Gallotta G, Boeri E, Lazzarin A. Pretreatment of chronic active hepatitis $\mathrm{C}$ in patients coinfected with HIV and hepatitis $\mathrm{C}$ virus reduces the hepatotoxicity associated with subsequent antiretroviral therapy. J Acquir Immune Defic Syndr 2003 Jun 1;33(2):146-52.

84. Martin-Carbonero L, Nunez M, Gonzalez-Lahoz J, Soriano V. Incidence of liver injury after beginning antiretroviral therapy with efavirenz or nevirapine. HIV Clin Trials 2003 Mar-Apr;4(2):115-20. 
85. Cavalheiro N P, Barone AA, Tengan FM. HCV serotypes in Brazilian patients. Int J Infect Dis 2002 Sep;6(3):228-32.

86. Cavalheiro NP. Análise dos sorotipos do VHC identificados em pacientes da cidade de São Paulo, através de método imunoenzimático [Dissertação de Mestrado]. São Paulo: Faculdade de Medicina da Universidade de São Paulo; 1999.

87. Frank C, Mohamed MK, Strickland GT, Lavanchy D, Arthur RR, Magder LS, El Khoby T, Abdel-Wahab Y, Aly Ohn ES, Anwar W, Sallam I. The role of parenteral antischistosomal therapy in the spread of hepatitis C virus in Egypt. Lancet 2000 Mar 11;355(9207):887-91.

88. Focaccia R, da Conceicao OJ, Sette H Jr, Sabino E, Bassit L, Nitrini DR, Lomar AV, Lorenco R, Vieira De Souza F, Kiffer CR, Santos EB, Gonzales MP, Saez-Alquezar A, Riscal JR, Fischer D. Estimated Prevalence of Viral Hepatitis in the General Population of the Municipality of Sao Paulo, Measured by a Serologic Survey of a Stratified, Randomized and Residence-Based Population. Braz J Infect Dis 1998 Dec;2(6):269284.

89. Carrasco Navarro R, Mendes-Corrêa MC, Barone AA. Soroconversão para o vírus da hepatite $\mathrm{C}$ em uma população previamente infectada pelo HIV na 
Casa da Aids de São Paulo. In: XXXIX Congresso da Sociedade Brasileira de Medicina Tropical; Belém, 2003. Tema Livre.

90. Pavan MH, Aoki FH, Monteiro DT, Goncales NS, Escanhoela CA, Goncales Junior FL. Viral hepatitis in patients infected with human immunodeficiency virus. Braz J Infect Dis 2003 Aug;7(4):253-61.

91. Aceti A, Pasquazzi C, Zechini B, De Bac C; LIVERHAART Group. Hepatotoxicity development during antiretroviral therapy containing protease inhibitors in patients with HIV: the role of hepatitis $\mathrm{B}$ and $\mathrm{C}$ virus infection. J Acquir Immune Defic Syndr 2002 Jan 1;29(1):41-8.

92. Martagon J, Gordon SM. Special management challenges in hepatitis C. Cleve Clin J Med 2003 Sep;70 Suppl 4:S27-33. Review.

93. Sulkowski MS, Thomas DL. Hepatitis C in the HIV-Infected Person. Ann Intern Med 2003 Feb 4;138(3):197-207. Review.

94. Martinez-Sierra C, Arizcorreta A, Diaz F, Roldan R, Martin-Herrera L, Perez-Guzman E, Giron-Gonzalez JA. Progression of chronic hepatitis C to liver fibrosis and cirrhosis in patients coinfected with hepatitis $\mathrm{C}$ virus and human immunodeficiency virus. Clin Infect Dis 2003 Feb 15;36(4):491-8. Epub 2003 Jan 31. 
95. Borgia G, Reynaud L, Gentile I, Piazza M. HIV and hepatitis C virus: facts and controversies. Infection 2003 Aug;31(4):232-40. Review.

96. Klein MB, Lalonde RG, Suissa S. The impact of hepatitis C virus coinfection on HIV progression before and after highly active antiretroviral therapy. $\mathbf{J}$ Acquir Immune Defic Syndr 2003 Jul 1;33(3):365-72.

97. De Bona A, Sitia G, Uberti-Foppa C, Galli L, Ciuffreda D, Gallotta G, Paties C, Lazzarin A. Impact of HAART on liver histology of HIV/HCV coinfected patients. J Biol Regul Homeost Agents 2003 AprJun;17(2):195-7.

98. Tamalet C, Colson P. Reciprocal influence of HIV and HCV infections in coinfected patients and the involvement of HAART. Clin Microbiol Infect 2003 Mar;9(3):159-60.

99. Sulkowski MS, Thomas DL. Hepatitis C in the HIV-infected patient. Clin Liver Dis 2003 Feb;7(1):179-94. Review.

100. Tornero C, Gimeno C, Igual R, Santamaria A, Gil E, Rull S. [Effect of HAART on HCV viral load in the first three years of follow-up]. Med Clin (Barcelona) 2003 Oct 4;121(11):408-9. 
101. Laurence J. HAART, hepatitis C, activated T cells, and mortality. AIDS Read 2003 Nov;13(11):510-1. 